\title{
Competição bancária, produtividade e desigualdade no Brasil: uma avaliação de equilíbrio geral
}

Rodrigo César Pacheco

Orientador: Prof. Dr. Gabriel de Abreu Madeira

São Paulo 
Prof. Dr. Vahan Agopyan

Reitor da Universidade de São Paulo

Prof. Dr. Fábio Frezatti

Diretor da Faculdade de Economia, Administração e Contabilidade

Prof. Dr. José Carlos de Souza Santos

Chefe do Departamento de Economia

Prof. Dr. Wilfredo Fernando Leiva Maldonado

Coordenador do Programa de Pós-Graduação em Economia 
Rodrigo César Pacheco

\section{Competição bancária, produtividade e desigualdade no Brasil: uma avaliação de equilíbrio geral}

Orientador: Prof. Dr. Gabriel de Abreu Madeira

Versão Corrigida

(versão original disponível na Biblioteca da Faculdade de Economia, Administração e Contabilidade)

São Paulo 
Catalogação na Publicação (CIP)

Ficha Catalográfica com dados inseridos pelo autor

\section{Pacheco, Rodrigo César.}

Competição bancária, produtividade e desigualdade no Brasil: uma avaliação de equilíbrio geral / Rodrigo César Pacheco. - São Paulo, 2021. $52 \mathrm{p}$.

Dissertação (Mestrado) - Universidade de São Paulo, 2021. Orientador: Gabriel de Abreu Madeira.

1. Sistema financeiro. 2. Competição bancária. 3. Hotelling. I. Universidade de São Paulo. Faculdade de Economia, Administração e Contabilidade. II. Título. 
Rodrigo César Pacheco

\section{Competição bancária, produtividade e desigualdade no Brasil: uma avaliação de equilíbrio geral}

Dissertação apresentada ao Departamento de Economia da Faculdade de Economia, Administração e Contabilidade da Universidade de São Paulo como requisito parcial para a obtenção do título de Mestre em Ciências

Prof. Dr. Gabriel de Abreu Madeira

Prof. Dr. Mauro Rodrigues Junior

Prof. Dr. Juliano Assunção

Prof. Dr. Tiago Vanderlei de

Vasconcelos Cavalcanti

São Paulo

2021 



\section{Agradecimentos}

Aos meus pais, Wilson e Márcia, por terem sempre me apoiado nas decisões, por mais estranhas que algumas delas parecessem, e por sempre terem feito da minha educação uma prioridade. À minha avó Diva, que me inspirou desde criança com sua curiosidade e sabedoria, mesmo privada de uma educação de qualidade quando jovem.

Ao meu orientador, Gabriel Madeira, pela paciência, dedicação e por todos os conselhos e sugestões nos últimos dois anos. Foi um prazer e um aprendizado enorme ter um orientador tão solícito e interessado no desenvolvimento deste trabalho. É difícil expressar toda a minha gratidão por todas as oportunidades e pela confiança depositada em mim.

Aos professores da FEA por todo o aprendizado. Em especial, ao David Turchick e Mauro Rodrigues, não apenas pelas interações acadêmicas e por todo o conhecimento compartilhado, mas também por terem um papel fundamental nesta etapa da minha vida acadêmica e pelo auxílio nas decisões de carreira. Ao Márcio Nakane pelas contribuições valiosas em versões anteriores deste trabalho.

Aos meus amigos do mestrado pelo companheirismo, pelas conversas e cafés na salinha, tornando a experiência do mestrado muito mais leve. Em especial, à Débora Oliveira, Lucas Chang e Rafael Oliveira por toda ajuda, paciência, aprendizado, apoio e por terem se tornado grandes amigos. Seria impossível concluir o mestrado sem o apoio de vocês.

Finalmente, agradeço ao apoio financeiro da CAPES. 



\section{Resumo}

Os níveis de spread, diferença entre as taxas de empréstimo e de captação de recursos dos bancos, praticados no Brasil destoam consideravelmente daqueles praticados no restante do mundo. Em 2018, enquanto o spread médio praticado no Brasil era 32\%, a média mundial era de 7\%. Ainda assim, os bancos são uma das principais fontes de recursos para financiamento de capital das empresas brasileiras. Combinando o modelo proposto em Aiyagari (1994) com bancos competindo à la Hotelling, buscamos entender o papel da competição bancária nos spreads praticados em operações com pessoas jurídicas e suas consequências em diversos indicadores econômicos, como: distribuição de tamanho de firmas, acesso à crédito, número de empreendedores e desigualdade de renda. Utilizando o ferramental introduzido em Achdou et al. (2021), solucionamos e calibramos o modelo para os dados brasileiros. Nossos resultados mostram que em um ambiente de competição perfeita, através da eliminação do custo de deslocamento para tomar empréstimo, teríamos uma redução de $13 \%$ no spread, um crescimento de aproximadamente $1.8 \%$ no produto, redução nos indicadores de desigualdade de renda e melhorias em bem-estar.

Palavras-chave: Sistema Financeiro. Competição Bancária. Hotelling. 



\section{Abstract}

The interest rate spread, the difference between the lending rate and deposit rate, in Brazil differs considerably from those charged in the rest of the world. In 2018, the interest rate spread in Brazil was close to $32 \%$. Meanwhile, the world average interest rate spread was less than 7\%. Despite the high rates seen in the country, Brazilian banks are one of the most important sources of capital financing for firms. We augment the model proposed in Aiyagari (1994), by introducing banks competing à la Hotelling, and use this to understand the role of banking competition in the interest rate spreads charged on firm's credit operations. Moreover, we evaluate some consequences of this imperfect competition on some economic indicators, such as the size distribution of firms, number of entrepreneurs, income inequality and financial inclusion. We leverage the framework developed in Achdou et al. (2021) to find the solution of the model and to match some of its results to the Brazilian data. Our quantitative analysis shows that eliminating the transportation cost, thus achieving a perfect competitive scenario, would increase the product by $1.8 \%$, reduce the interest rate spreads by $13 \%$, produce welfare gains and contribute to reduce income inequality in the country.

Keywords: Financial System. Banking Competition. Hotelling. 



\section{Lista de ilustrações}

Figura 1 - Evolução do spread no Brasil e no mundo . . . . . . . . . . . . . . 1

Figura 2 - Share de ativos dos cinco maiores bancos . . . . . . . . . . 6

Figura 3 - Comparativo spread e indicadores de mercado por país . . . . . . . . 7

Figura 4 - Composição da carteira de crédito . . . . . . . . . . . . . 8

Figura 5 - Evolução do spread no Brasil . . . . . . . . . . . . . . . . 9

Figura 6 - Composição do spread brasileiro . . . . . . . . . . . . . . . . . 9

Figura 7 - Custo de deslocamento ao tomar empréstimo . . . . . . . . . . . 12

Figura 8 - Sequência de eventos . . . . . . . . . . . . . . . . . . 14

Figura 9 - Disposição dos bancos . . . . . . . . . . . . . . 18

Figura 10 - Características dos indivíduos e firmas por posição . . . . . . . . . . . 22

Figura 11 - Distribuição de indivíduos por tamanho de empresa e forma de financiamento . . . . . . . . . . . . . . . . . . . 28

Figura 12 - Forma de financiamento de capital . . . . . . . . . . . . . 38

Figura 13 - Escolha ocupacional . . . . . . . . . . . . . . . . . . . . 40 



\section{Lista de tabelas}

Tabela 1 - Parâmetros dos grids . . . . . . . . . . . . . 17

Tabela 2 - Parâmetros do modelo . . . . . . . . . . . . . . 20

Tabela 3 - Ajuste do modelo aos dados . . . . . . . . . . . . . 20

Tabela 4 - Resultados de estado estacionário . . . . . . . . . . . . . . . 22

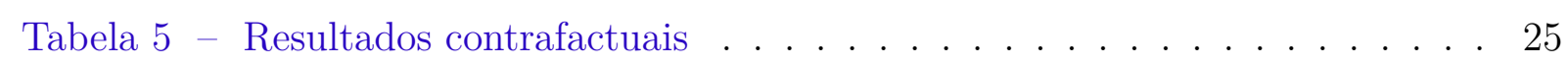





\section{Notação e Símbolos}

\section{Notação}

$$
\begin{array}{ll}
x^{+} & \operatorname{máx}\{x, 0\} \\
x^{-} & \min \{x, 0\} \\
\operatorname{card}(A) & \text { Número de elementos do conjunto A }
\end{array}
$$

\section{Símbolos}

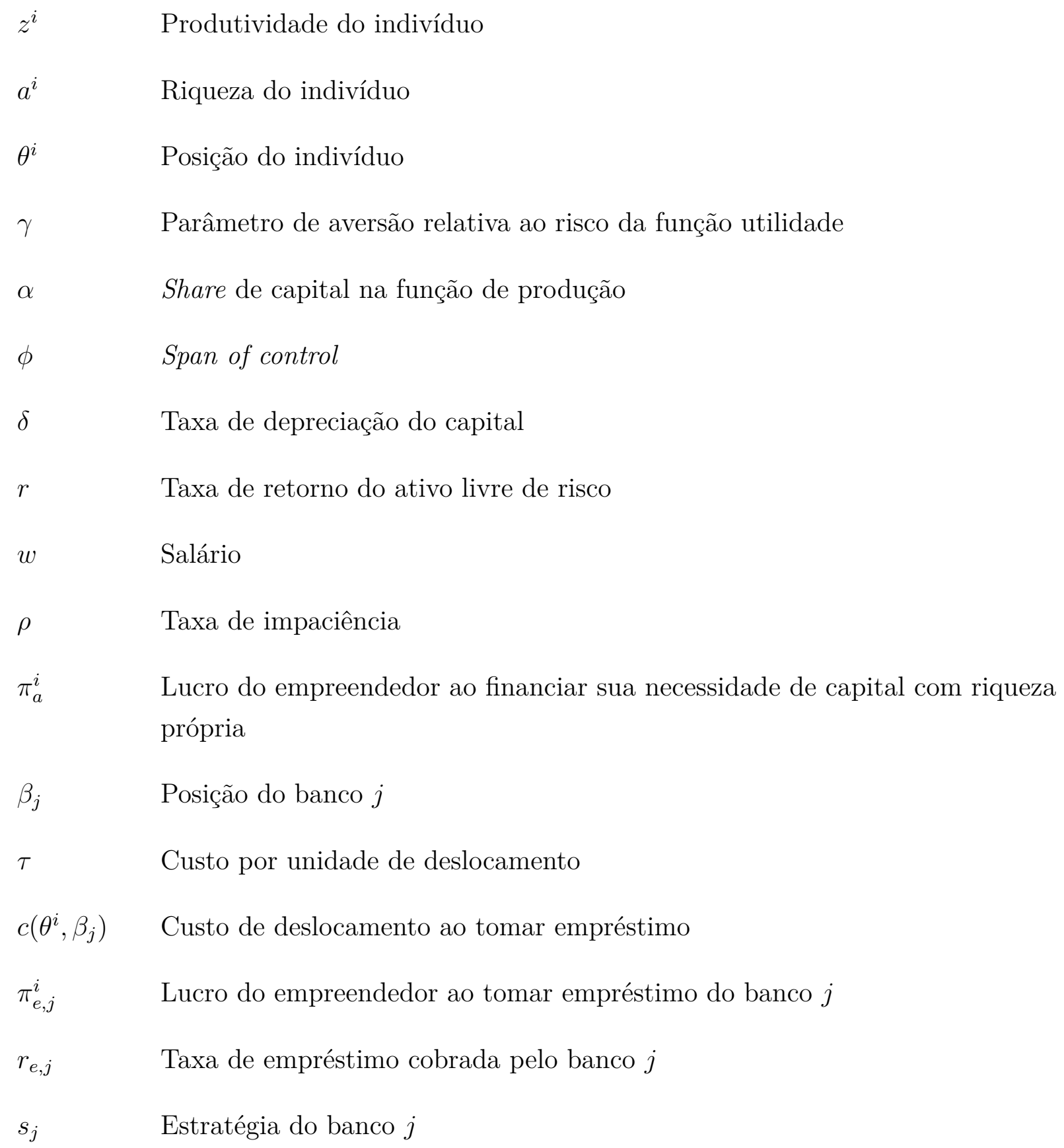


Parcela do spread correspondente a tributos, custos administrativos e inadimplência

$\lambda \quad$ Restrição de endividamento do indivíduo

$\eta \quad$ Fração de riqueza que é confiscada em caso de default

$j_{i}^{\prime} \quad$ Banco que maximiza o lucro do indivíduo $i$ quando este toma empréstimo

$\pi_{e, j_{i}^{\prime}}^{i} \quad$ Lucro máximo do empreendedor ao emprestar

$\pi^{i} \quad$ Lucro máximo do empreendedor

$y^{i} \quad$ Renda do indivíduo

$g(a, z, \theta) \quad$ Distribuição conjunta de riqueza, produtividade e posição dos indivíduos

s Estratégia conjunta dos bancos

$d_{j}\left(s_{j}, \mathbf{s}_{-j}\right) \quad$ Demanda por empréstimo ao banco $j$

Alíquota de depósito compulsório 


\section{Sumário}

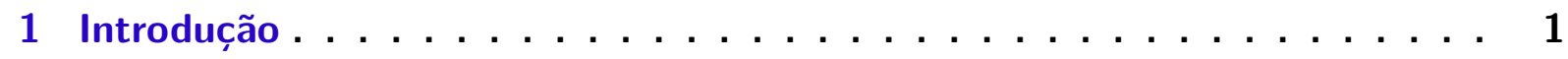

2 Sistema Financeiro Brasileiro $\ldots \ldots \ldots \ldots \ldots \ldots \ldots$

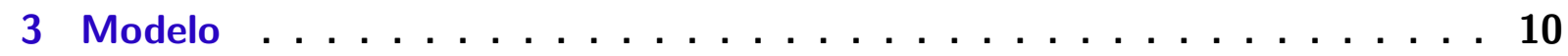

3.1 Descrição do Modelo . . . . . . . . . . . . . . . . . . . . . . . . 10

3.2 Solução do Modelo . . . . . . . . . . . . . . . . . . . . 16

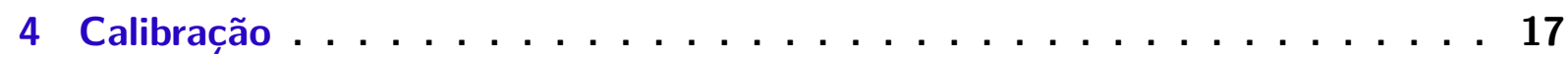

5 Resultados . . . . . . . . . . . . . . . . . . . 21

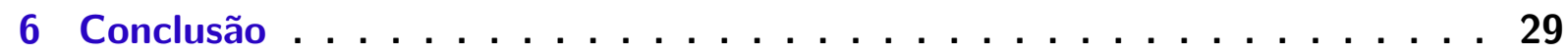

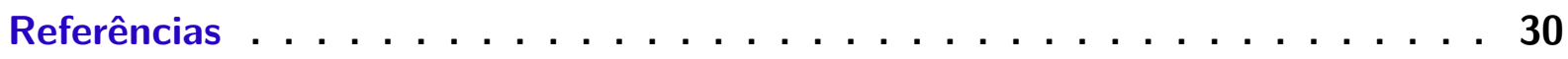

Apêndices 33

APÊNDICE A Derivações Teóricas . . . . . . . . . . . . . . 34

A.1 Hamilton-Jacobi-Bellman . . . . . . . . . . . . . . 34

A.2 Problema da Firma . . . . . . . . . . . . . . . . 35

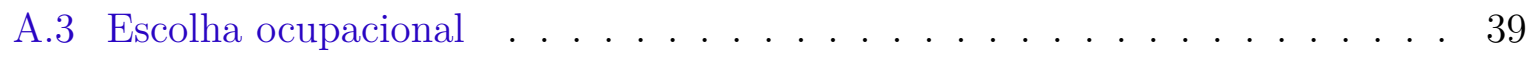

APÊNDICE B Solução do Modelo . . . . . . . . . . . . 41

B.1 Problema do Indivíduo . . . . . . . . . . . . . . . . . . . . 41

B.2 Market clearing . . . . . . . . . . . . . . . . . . 49

B.3 Problema dos Bancos . . . . . . . . . . . . . . . . . . . . . . 49

B.3.1 Caso simétrico. . . . . . . . . . . . . . . . . . . . . . . . 49

B.3.2 Caso não simétrico $\ldots \ldots \ldots \ldots \ldots \ldots \ldots$

APÊNDICE C Algoritmos . . . . . . . . . . . . . 51

C.1 Problema do Indivíduo . . . . . . . . . . . . . . . . . . . . 51

C.2 Equilíbrio de Estado Estacionário . . . . . . . . . . . . . . 51 



\section{Introdução}

Os níveis de spread, diferença entre a taxa de empréstimo e a taxa de captação de recursos dos bancos, praticados no Brasil destoam consideravelmente daqueles praticados no restante do mundo. No início de 2018, o spread médio no Brasil era de $32 \%$, enquanto a média mundial era de 7\%. Tal diferença ainda persiste quando comparamos o Brasil aos demais países da América Latina (7.1\%) e aos demais países emergentes (7.8\%)ํ․ A Fig. 1 compara a evolução dos spreads praticados no Brasil com os demais países da América Latina, emergentes e o restante do mundo.

Apesar das elevadas taxas, os bancos possuem um papel de destaque no financiamento das firmas no país. Pelo menos $43 \%$ das firmas brasileiras utilizavam bancos para financiar seus investimentos em 2017, valor bastante superior à média mundial de $25.1 \%$. Além disso, em uma pesquisa conduzida pelo Banco Mundial em 2009, 45\% das firmas brasileiras entrevistadas apontaram o acesso a financiamento como a maior restrição aos negócios enfrentada pela empresa. Na América Latina e no mundo este percentual foi $18 \%$ e $24 \%$, respectivamente. ${ }^{2}$

Figura 1 - Evolução do spread no Brasil e no mundo

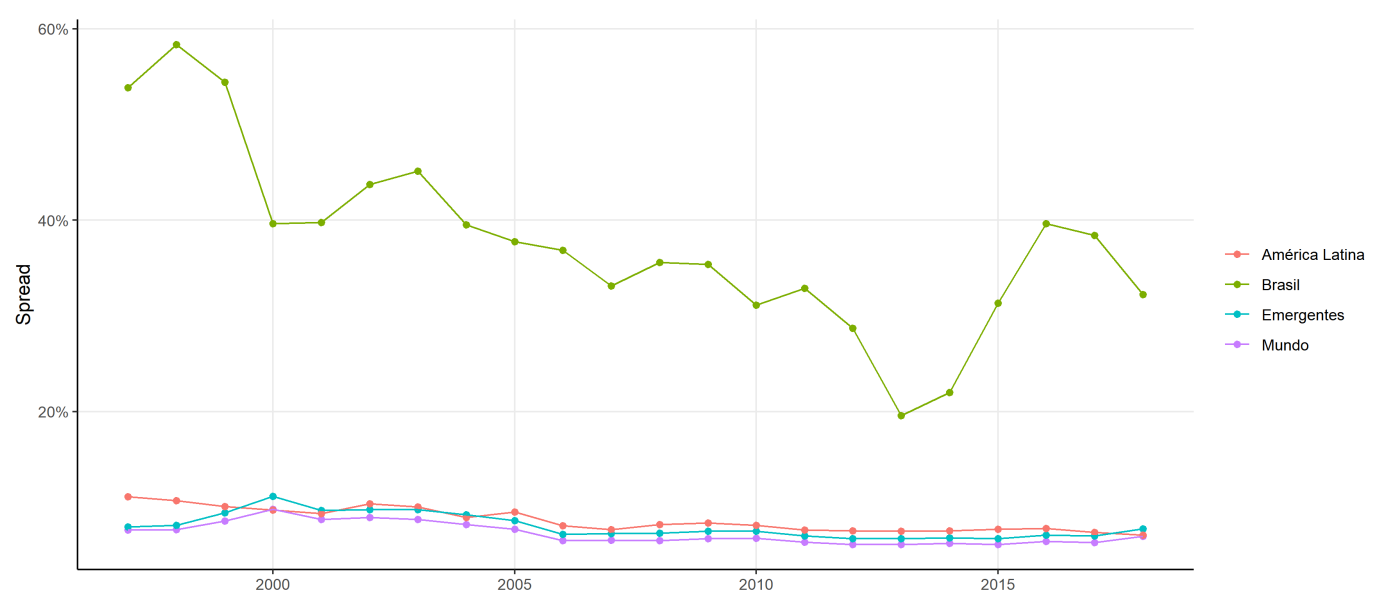

Fonte - World Bank Data. Elaboração própria.

Dado a relevância do sistema bancário para o país e as altas taxas encontradas aqui, procuramos, neste trabalho, entender qual o papel da competição entre bancos nos spreads das operações de crédito envolvendo empresas e suas consequências em diversos outros indicadores, como distribuição de tamanho de firmas, número de empreendedores, bem-estar e medidas de desigualdade de renda. Mais especificamente, procuramos entender

1 Global Financial Development Report 2019/2020: Bank Regulation and Supervision a Decade after the Global Financial Crisis

2 Enterprise Surveys - Banco Mundial 
quais os efeitos nestes indicadores da existência de heterogeneidade no relacionamento entre firmas e bancos, em que temos diferentes graus de "proximidade" entre estes dois agentes.

Propomos então um modelo baseado em Aiyagari (1994) com agentes heterogêneos em três dimensões: riqueza, produtividade e distância em relação aos bancos. Com base nestas características, os indivíduos escolhem entre trabalhar ou empreender. Os empreendedores podem financiar sua necessidade de capital através da sua riqueza e, caso não seja suficiente, podem tomar um empréstimo de um dos bancos disponíveis nesta economia. Caso decidam emprestar, além de pagar uma taxa pelo empréstimo, os indivíduos incorrem em um custo de "deslocamento" adicional para acessar cada um dos bancos, como proposto em Hotelling (1929). Tal custo de deslocamento é o cerne do modelo, conferindo poder de mercado aos bancos, que competem entre si em um jogo não cooperativo.

Apesar da interpretação usual deste custo como consequência do deslocamento físico até cada um dos bancos, procuramos interpretar tal custo de forma mais abstrata e abrangente, incorporando mais fatores, como, por exemplo, custo de obtenção e fornecimento de informações financeiras por parte das firmas para atender às exigências dos bancos na concessão dos empréstimos. Desta forma, uma empresa com relacionamento mais "próximo" a um banco tem um custo menor de fornecer tais informações, devido ao seu histórico de relacionamento com aquele banco, por exemplo.

Como argumentado em Boot (2000) sobre os efeitos do "Relationship Banking", um determinado banco com um relacionamento prévio com uma certa firma possui uma série de informações sobre ela não disponíveis para os demais bancos do mercado. Esta firma pode ter adquirido outros produtos do banco, como conta corrente e serviços de folha de pagamento, que fornecem informações adicionais a este banco, ajudando, por exemplo, na avaliação do risco de crédito desta empresa.

Além disso, como apontado em Petersen e Rajan (2002), informações subjetivas (soft information $)^{4}$ têm papel importante no processo de decisão de concessão de empréstimos dos bancos, principalmente para firmas pequenas, e o relacionamento entre firma e banco é uma fonte importante deste tipo de informação. Drexler e Schoar (2014) mostram, utilizando dados de empréstimos para pequenas empresas no Chile, que o rompimento da relação entre o gerente do banco e uma firma tem impactos diretos na concessão de crédito. Em particular, eventos inesperados, como afastamento por motivos de doença de um gerente, reduzem a probabilidade de aprovação de um novo empréstimo das firmas

3 Boot (2000) define "Relationship Banking" como sendo a provisão de serviços financeiros em que o intermediador investe recursos para obter informações específicas do seu cliente, avaliando o retorno de tal investimento a partir de múltiplas interações com o cliente tanto no tempo como através de múltiplos produtos ofertados.

4 Por informação subjetiva nos referimos ao tipo de informação que é difícil de transmitir para outras pessoas, ou capturá-la através de documentos. Um exemplo seria o quão confiável o gerente de um banco considera o dono de uma empresa, ou quão apto este gerente o considera para administrá-la. 
que eram previamente atendidas por este gerente neste banco. Aumentam, ainda, tanto a probabilidade de solicitarem empréstimos em outros bancos como de se tornarem inadimplentes. Tais efeitos são maiores quanto menor for o empréstimo e pior for o score de crédito associado a firma.

Sobre o papel da distância física no mercado de crédito, há evidências de que a distância entre bancos e firmas esteja aumentando, com as firmas tomando empréstimos de filiais cada vez mais distantes delas, conforme mostram Petersen e Rajan (2002) para os Estados Unidos analisando o período 1983-1993. Os autores atribuem este aumento na distância aos avanços tecnológicos e a maior disponibilidade de dados financeiros das pequenas firmas. Isto gera, no processo de decisão de concessão de empréstimos, um efeito substituição entre informações do tipo soft, que requerem um contato mais próximo às firmas, por informações quantitativas (hard).

Porém, a distância ainda é um fator importante para o mercado de crédito, principalmente para os empréstimos destinados às pequenas firmas. Agarwal (2010) mostra, utilizando dados de 2003 para os Estados Unidos, que quanto mais próximos as empresas estão de uma filial de um banco, maior a chance de terem seus pedidos de empréstimos aprovados, apesar de pagarem taxas mais altas por isso. O autor atribuí tal efeito ao papel que informações subjetivas têm no processo de concessão de empréstimos.

Utilizando dados mais recentes, de 1999 a 2012, para os Estados Unidos, Nguyen (2019) mostra que o mercado de crédito para pequenas firmas continua dependente da proximidade geográfica entre as firmas e as filiais dos bancos. Utilizando episódios de fusões entre instituições financeiras como fonte exógena de variação, o autor conclui que há redução no volume de crédito ofertado às pequenas empresas nas regiões em que existiam pelo menos duas filiais de bancos que se fundiram e ao menos uma delas foi fechada. Este efeito ocorre mesmo em mercados com grande número de bancos e decresce de forma quase monotônica com a distância em relação à filial que foi fechada. Além disso, o número de novos empréstimos para pequenas firmas não volta a crescer mesmo após novas filiais de outros bancos entrarem na região em que ocorreu a fusão, corroborando com a tese de que o relacionamento e informações subjetivas são as causas destes efeitos observados.

Na Bélgica, Degryse e Ongena (2005) encontram evidências da existência de uma política de discriminação de preços relacionada com a distância entre bancos e firmas. Firmas mais próximas ao banco pagam taxas mais altas quando comparadas às firmas mais distantes. Mesmo controlando por variáveis de relacionamento, o efeito permanece. Logo, os autores atribuem este efeito a custos de transporte e não ao papel do relacionamento e aquisição de soft information.

Há ainda uma vasta literatura dedicada ao mercado de crédito no Brasil com a qual este trabalho está relacionado. Sobre a competição no sistema bancário, Joaquim, Doornik e Ornelas (2019) utilizam os episódios de M\&A de bancos brasileiros como fonte 
exógena de variação na identificação dos efeitos causais decorrentes de competição no sistema bancário. Os autores encontram evidências de que a fusão de instituições bancárias causa um aumento de 5.88 p.p. no spread e uma redução de $10 \%$ no volume de crédito ofertado três anos após a fusão.

Com o objetivo de avaliar a relação entre competição no setor bancário e propensão ao risco das instituições financeiras, Tabak, Fazio e Cajueiro (2012) estimam o indicador de Boone ${ }^{5}$ para vários países da América Latina. Os resultados mostram que os países da América Latina, em média, têm um grau menor de competição quando comparados com os Estados Unidos e países europeus. Analisando o período de 2001 a 2008, os autores concluem que o nível de competição no Brasil diminuiu, ao contrário do que ocorreu na Argentina, Colômbia e México, por exemplo.

Ainda com relação à competição no sistema financeiro brasileiro, Sanches, Rocha e Silva (2009) estimam um modelo estrutural regional de competição bancária, baseado em Nakane (2002) que estima um modelo semelhante a nível nacional. Ambos concluem que há um nível alto de competição no sistema financeiro, embora rejeitem a hipótese de competição perfeita no setor quando considerado ao nível nacional. Sanches, Rocha e Silva (2009) encontram evidências de heterogeneidade no nível de competição bancária entre os estados, com alguns estados tendo mercados mais competitivos, Paraná, Ceará e Bahia, por exemplo, e outros menos competitivos, Minas Gerais, Rio de Janeiro e São Paulo, por exemplo.

Cavalcanti et al. (2021) estudam os efeitos relacionados a elevada variância presente nos spreads praticados no Brasil. Em particular, firmas mais jovens e menores tendem a pagar taxas mais altas do que firmas mais velhas e maiores. A eliminação desta variância, mantendo o nível médio de spread, traria consequências positivas, como aumento de empreendedores, produto e oferta de crédito na economia, além de redução da dispersão no tamanho das firmas. Os autores avaliam ainda os efeitos da existência de comprometimento limitado nos contratos de empréstimo no país, apontando que melhorias na tecnologia de monitoramento ou reformas na legislação que aumentassem o poder de execução destes contratos trariam consequências positivas semelhantes.

Sobre o efeito do direcionamento do crédito no Brasil, Madeira et al. (2018) utilizam um modelo com agentes heterogêneos em tempo contínuo com escolha ocupacional endógena, semelhante ao modelo usado neste trabalho. Dentre os resultados, os autores encontram que a extinção do programa de direcionamento de crédito no país traria ganhos positivos em termos de bem-estar, com redução de desigualdade e do tamanho médio das firmas, aumento da produtividade e maior inclusão financeira. Tais benefícios são

$\overline{5}$ O indicador de Boone, proposto em Boone (2008), baseia-se na hipótese de que a competição aumenta a performance, medida através do lucro ou de market share, de empresas mais eficientes e reduz a performance das menos eficientes. Quanto maior o efeito da eficiência na performance das firmas, maior o grau de competição atribuído a este mercado. 
ainda superiores quando comparados àqueles gerados por uma política de direcionamento alternativa que focasse apenas em agentes mais pobres ou mais produtivos. Souza-Sobrinho (2009) estima tanto o impacto do direcionamento de crédito quanto do depósito compulsório no spread brasileiro. Utilizam, para isso, um modelo de equilíbrio geral com agente representativo. Segundo estimativas do autor, as políticas de direcionamento de crédito e os recolhimentos compulsórios correspondem respectivamente a $28 \%$ e $16 \%$ do spread brasileiro ${ }^{6}$.

Nossa principal contribuição à literatura já existente é identificar dois canais relacionados aos efeitos da "proximidade" em termos de relacionamento entre bancos e firmas. O primeiro e mais evidente efeito é que a introdução deste custo de deslocamento gera poder de mercado aos bancos e, consequentemente, um spread, em equilíbrio, que atinge todos os indivíduos desta economia da mesma forma. Temos, portanto, uma componente do spread endógena. Variando este custo de deslocamento, podemos medir qual o impacto correspondente no spread de equilíbrio. O segundo canal está relacionado à heterogeneidade na distância entre indivíduos e firmas. Alguns indivíduos, por sorte, estão localizados na mesma posição de um banco, não pagando custo de deslocamento algum para acessá-lo. Comparando estes indivíduos com aqueles localizados em diferentes distâncias dos bancos, podemos entender como eles diferem em relação ao, por exemplo, percentual de agentes que decidem empreender, distribuição de tamanho das firmas, acesso a crédito e medidas de desigualdade de renda. Como todos os indivíduos estão sujeitos à mesma taxa de empréstimo, mas parte deles não são afetados pelo custo de deslocamento, o modelo permite separar os dois canais mencionados.

O restante deste texto está organizado da seguinte forma: o Capítulo 2 apresenta diversas características do sistema financeiro brasileiro, comparando este com os demais sistemas financeiros do mundo. O Capítulo 3 define o modelo utilizado. O Capítulo 4 apresenta os parâmetros utilizados para calibrar o modelo e compara os momentos gerados por este com os respectivos momentos observados nos dados brasileiros. O Capítulo 5 apresenta os resultados dos exercícios contrafactuais realizados e, por fim, o Capítulo 6 conclui.

6 Vale ressaltar que, na época do estudo, a alíquota efetiva do depósito compulsório era próxima a $29 \%$. Em 2019, esta alíquota era aproximadamente $23 \%$ 


\section{Sistema Financeiro Brasileiro}

O setor bancário possui um elevado índice de concentração em todo o mundo. O share de ativos dos cinco maiores bancos é uma medida frequentemente utilizada para avaliar o grau de concentração bancária em cada país. Em 2017, a média deste indicador era de aproximadamente $78 \%$ no mundo. Apesar de ter apresentado oscilações nos últimos 20 anos, o valor do índice em 2017 é praticamente o mesmo de 1996. Por outro lado, alguns países viram este índice crescer no mesmo período, como Estados Unidos, Argentina, Canadá, Chile e Brasil. Em 1996, os cinco maiores bancos brasileiros detinham 51\% dos ativos, ao passo que em 2017, $83 \%$ dos ativos estavam concentrados nos cinco maiores bancos. O maior salto do índice neste período ocorreu entre 2008 e 2009, com um aumento de aproximadamente 15 p.p. ${ }^{1}$. Apesar do aumento na concentração do setor no país, o índice de Boone para o mesmo período permaneceu aproximadamente constante, indicando, ao menos sob a ótica deste indicador, que o nível de competição no setor permaneceu constante $^{2}$. A Fig. 2 mostra a evolução do share de ativos dos cinco maiores bancos no Brasil e no mundo.

Figura 2 - Share de ativos dos cinco maiores bancos

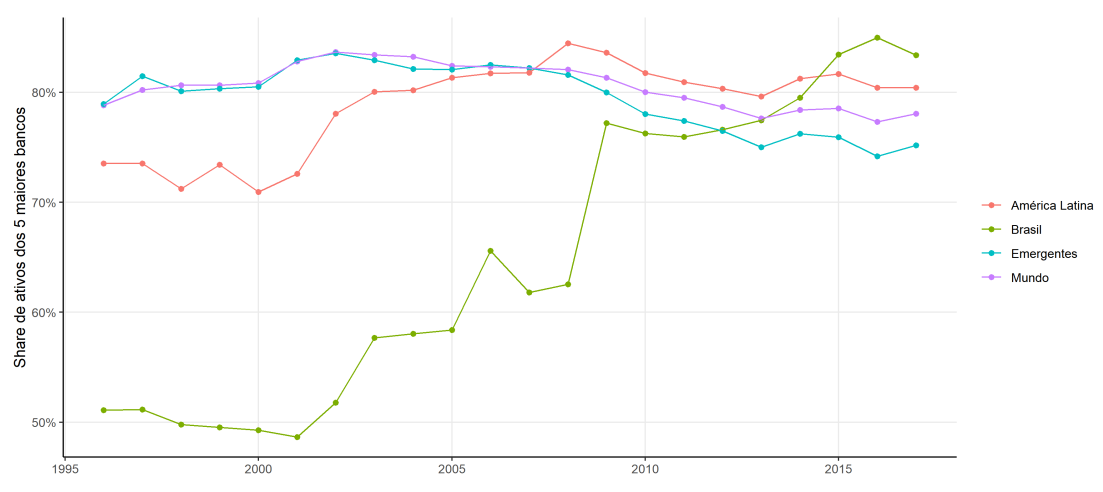

Fonte - Banco Mundial - Elaboração própria.

A Fig. 3 traz um comparativo entre vários países de diversos indicadores do sistema financeiro em 2017. Sobre às exigências de capital e reservas em relação aos ativos das instituições financeiras, o percentual encontrado para o Brasil (10.1\%) é ligeiramente inferior à mediana mundial (10.9\%). Sobre a inadimplência no país, é possível notar que o percentual da carteira de ativos em atraso (3.6\%) é próximo à mediana mundial (3.7\%). No entanto, a taxa de recuperação de créditos em default no Brasil (13.7\%) está entre as

1 Em 2008 ocorreram fusões de grandes instituições financeiras brasileiras, como: Santander e ABN AMRO Real, Banco do Brasil e Banco de Santa Catarina, Itaú e Unibanco (JOAQUIM; DOORNIK; ORNELAS, 2019).

2 Segundo Banco Central do Brasil (2019), o índice de Boone de crédito em 2001 e 2019 foi de aproximadamente -0.2 . 
menores do mundo, ocupando o $11^{\mathrm{O}}$ lugar dentre 166 países. A mediana deste indicador no mundo é de $37.1 \%$. Por fim, com relação aos custos operacionais dos bancos, a razão entre estes custos e as receitas dos bancos no país (64.4\%) é relativamente próxima à mediana mundial $(56.4 \%)^{3}$.

Figura 3 - Comparativo spread e indicadores de mercado por país

(a) Spread $\times \%$ capital sobre ativos

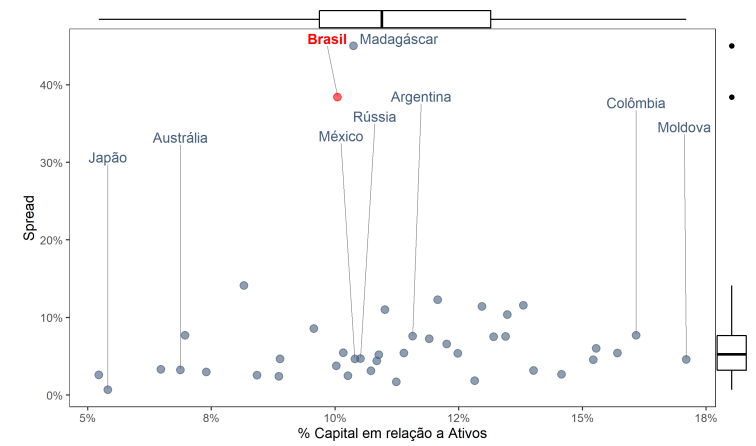

(c) Spread $\times$ taxa de recuperação

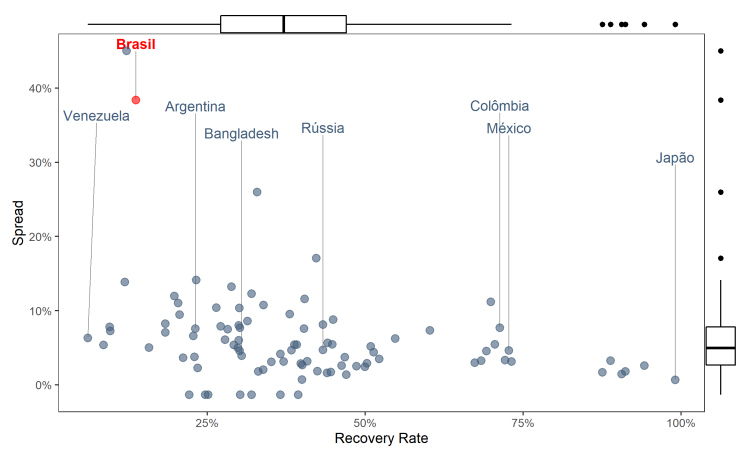

(b) Spread $\times$ inadimplência

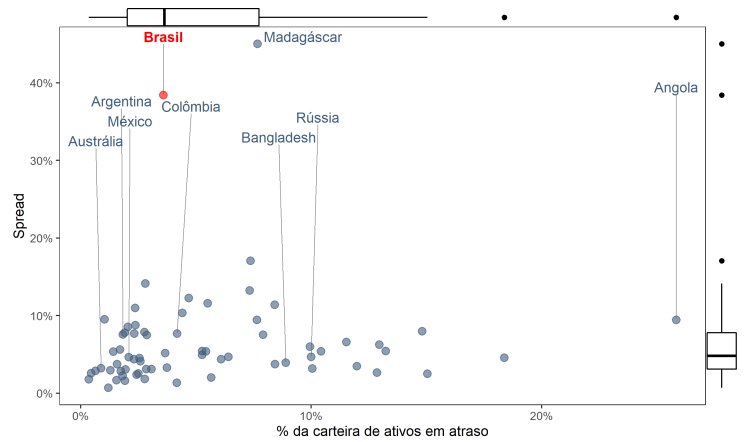

(d) Spread $\times \%$ Custos Operacionais

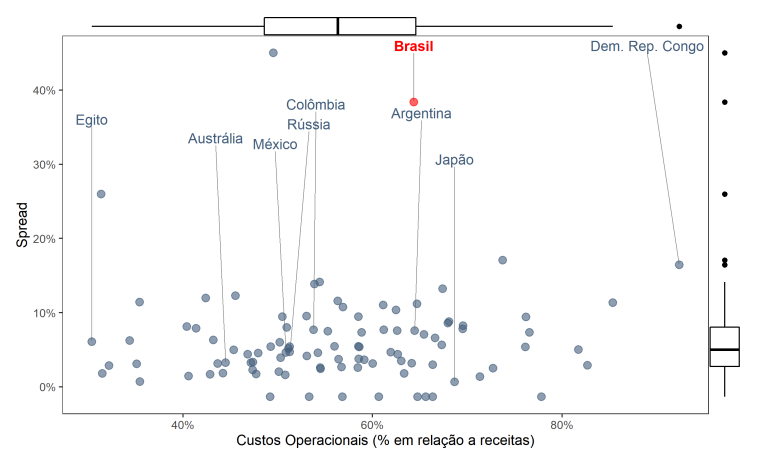

Fonte - Banco Mundial. Elaboração própria.

Como mencionado anteriormente, os bancos desempenham um papel importante no financiamento das firmas no país, tanto nos investimentos, como também nas necessidades de capital de giro. Em 2017, 52.3\% das firmas brasileiras utilizavam bancos para financiar suas necessidades de capital de giro, enquanto no mundo a média era de $28.1 \%$. Além disso, o mercado de títulos de dívidas corporativas no país é ainda bastante incipiente, o que amplifica a importância das instituições financeiras para as firmas. Considerando o saldo total de títulos de dívidas emitidos no país em 2020, apenas 5.5\% eram de empresas não ligadas ao setor financeiro. A título de comparação, no mesmo ano, nos Estados Unidos, França, Chile e Argentina esse valor era, respectivamente, de 15.6\%, 15.5\%, $9.4 \%$ e 29.6\% .

A Fig. 4a traz a composição da carteira de crédito do país por origem e destino dos recursos. Em 2020, aproximadamente 44\% do volume emprestado era destinado a

3 Combinando as quatro variáveis mencionadas neste parágrafo com o share de ativos dos cinco maiores bancos, explicaríamos 11.9p.p. dos 38.4 p.p. de spread brasileiro em 2017, com base em uma regressão para os dados dos países da Fig. 3.

4 Bank for International Settlements (BIS) 
empresas, sendo $45 \%$ deste com algum tipo de subsídio. A Fig. 4b mostra a distribuição do volume emprestado por porte de empresa. Em 2020 as grandes empresas respondiam por $60 \%$ do total, seguidas das médias, pequenas e microempresas, estas últimas respondendo por menos de $3 \%$ do volume emprestado. É possível notar ainda que houve uma redução na fração de crédito subsidiado nos últimos 4 anos, causada principalmente pela redução na participação deste tipo de empréstimo para empresas. Analisando a composição da carteira de crédito por tipo de controle da instituição financeira, nota-se uma redução na participação de bancos cujo controle é público nos últimos anos. Ainda assim, em 2020 estes bancos responderam por $45 \%$ do volume emprestado.

Figura 4 - Composição da carteira de crédito

(a) Por contraparte e origem dos recursos
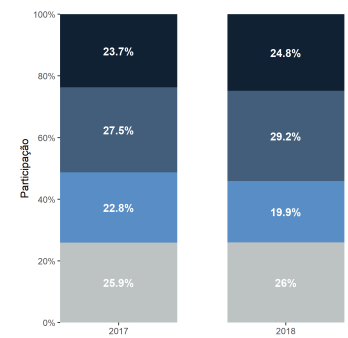

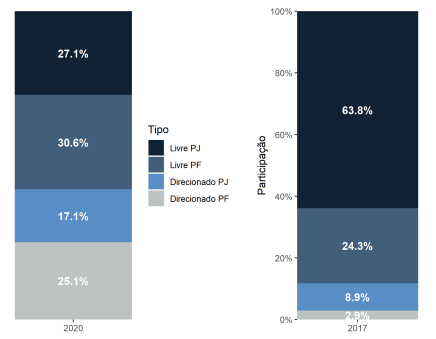

(b) Empresas: por porte
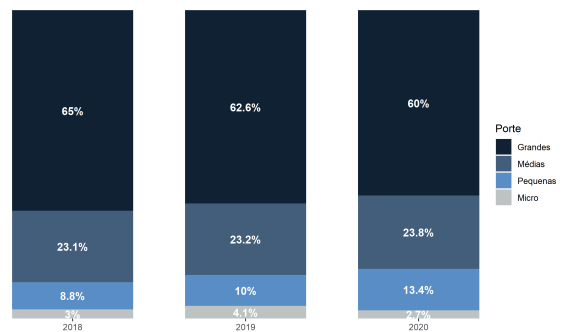

(c) Por tipo de controle da instituição financeira
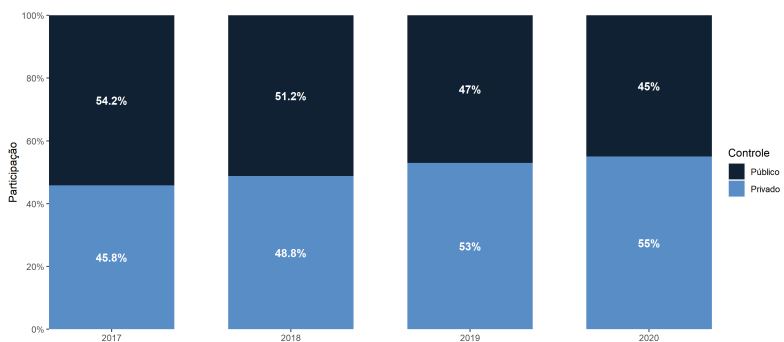

Fonte - Banco Central (SGS). Elaboração própria.

Há também uma elevada heterogeneidade nos spreads praticados no Brasil de acordo com o tipo de contraparte e origem dos recursos. A Fig. 5a mostra a diferença entre os spreads praticados nas operações com pessoas físicas e jurídicas. Nota-se que, historicamente, os spreads praticados em operações com pessoas físicas são maiores que aqueles praticadas em operações com empresas. No início de 2020 essa diferença era de aproximadamente 14 p.p.. Com relação à origem dos recursos dos empréstimos para empresas, o spread médio das operações subsidiadas é substancialmente mais baixo, como pode ser visto na Fig. 5b. A diferença entre ambos era de aproximadamente 7 p.p. em 2020. Como também salientado em Cavalcanti et al. (2021), há uma elevada variância dos spreads em relação ao porte das empresas. Em 2018, as grandes empresas pagavam taxas, em média, 13 p.p. inferiores àquelas pagas por micro e pequenas empresas ${ }^{5}$.

\footnotetext{
5 Financing SMEs and Entrepreneurs 2020: An OECD Scoreboard
} 
Figura 5 - Evolução do spread no Brasil

(a) Por tipo de contraparte

(b) Empresas: origem dos recursos
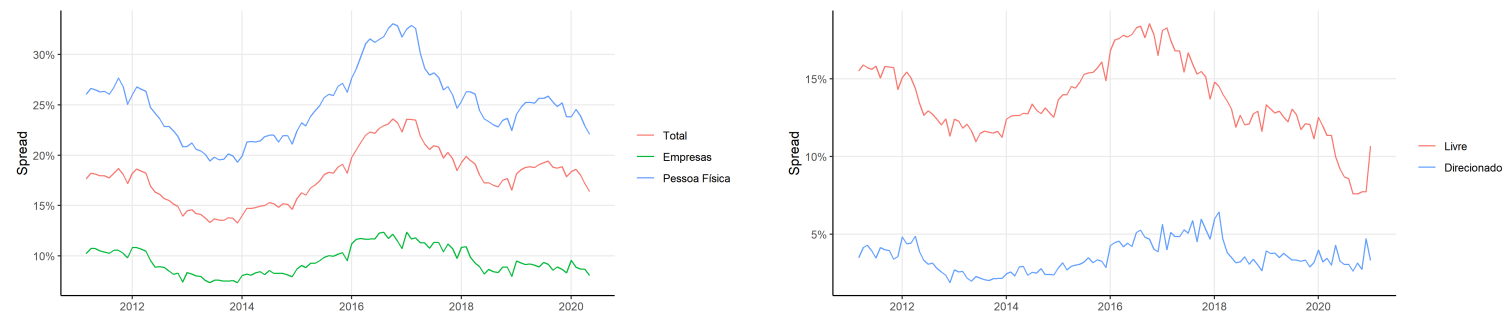

Fonte - Banco Central (SGS). Elaboração própria.

O Banco Central divulga periodicamente o Relatório de Economia Bancária ${ }^{6}$. Neste documento, o órgão traz estimativas da participação da inadimplência, despesas administrativas, tributos e margem financeira no spread. A Fig. 6 traz estas estimativas para os anos de 2017, 2018 e 2019. Nota-se que margem financeira e despesas administrativas respondem, nestes anos, por mais de $40 \%$ do spread, o equivalente, em 2019, a aproximadamente 7 p.p..

Figura 6 - Composição do spread brasileiro
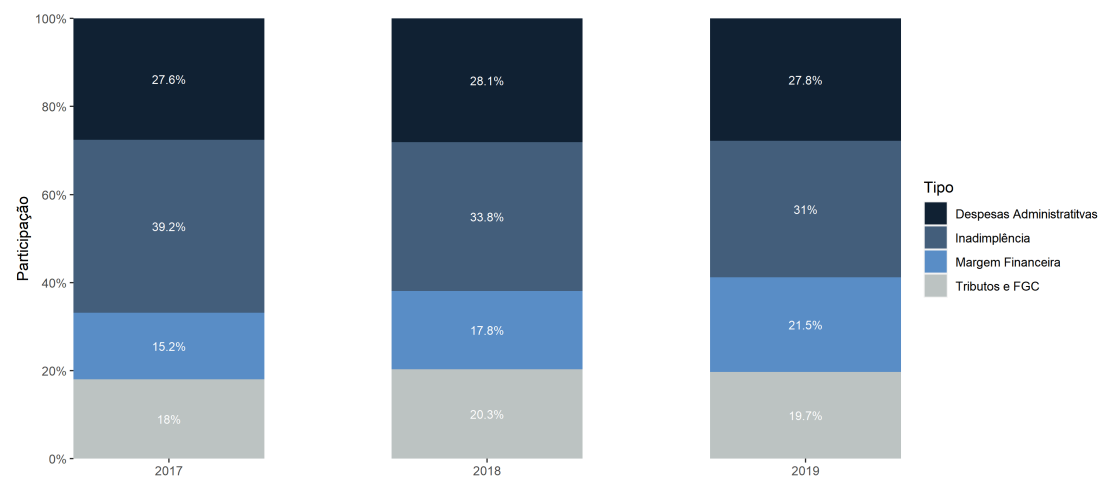

Fonte - Relatório de Economia Bancária - BCB. Elaboração própria.

6 Banco Central do Brasil (2019). 


\section{Modelo}

Utiliza-se um modelo em tempo contínuo com agentes heterogêneos em três dimensões: produtividade, $z$, riqueza, $a$, e posição em uma circunferência de raio unitário, $\theta$. Indivíduos estão sujeitos a choques idiossincráticos de produtividade ao longo do tempo e escolhem entre trabalhar ou empreender, em uma formulação semelhante a Lucas (1978). Ao contrário da produtividade e da riqueza que evoluem ao longo do tempo, a posição de cada indivíduo é fixada no instante inicial.

Caso decidam empreender, indivíduos têm a possibilidade de tomar empréstimo de um dos bancos para financiar sua necessidade de capital. Ao tomar empréstimo, o indivíduo incorre em um custo de deslocamento até o banco, que ocupa uma posição ao longo da circunferência, como no modelo proposto em Hotelling (1929). Cada banco escolhe a sua taxa de empréstimo de forma a maximizar seu lucro, tomando como dado as taxas praticadas pelos demais bancos.

No decorrer da próxima seção, com o intuito de facilitar a notação, quando nos referirmos ao indivíduo $i$, estaremos implicitamente nos referindo ao indivíduo cuja riqueza é $a$, produtividade é $z$ e posição é $\theta$. O mesmo vale quando indicarmos alguma variável com o sobrescrito $i$. Por exemplo, $\pi^{i}$, é o lucro da firma do indivíduo com riqueza $a$, produtividade $z$ e posição $\theta$.

\subsection{Descrição do Modelo}

Há um contínuo de agentes heterogêneos com massa unitária em três dimensões: produtividade, $z^{i}$, riqueza, $a^{i}$, e posição, em coordenadas polares, em uma circunferência de raio unitário, sendo $\theta^{i} \in[0,2 \pi)$ o ângulo polar. Agentes estão distribuídos uniformemente ao longo da circunferência, e a posição de cada indivíduo é fixada em $t=0$. Indivíduos extraem utilidade apenas do consumo do único bem da economia. A utilidade do indivíduo é representada por uma função do tipo CRRA (Constant Relative Risk Aversion):

$$
u\left(c_{t}\right)=\frac{c_{t}^{1-\gamma}}{1-\gamma}, \quad \gamma>0
$$

A produtividade de cada indivíduo evolui de forma que $\ln z_{t}$ segue um processo de difusão de Ornstein-Uhlenbeck, isto é:

$$
\mathrm{d} \ln z_{t}=-\varphi \ln z_{t} \mathrm{~d} t+\zeta \mathrm{d} W_{t}, \quad \operatorname{com} \varphi>0 \text { e } \zeta>0
$$

em que $W_{t}$ denota o processo de Wiener ${ }^{1}$.

\footnotetext{
1 Note que os choques idiossincráticos de produtividade independem da posição de cada indivíduo.
} 
Em cada instante de tempo o indivíduo pode escolher entre trabalhar, recebendo um salário $w_{t}$, ou empreender, contratando capital, $k_{t}$, e trabalho, $\ell_{t}$, para produzir o único bem da economia. A função de produção da firma é dada por:

$$
f\left(z_{t}^{i}, k_{t}, \ell_{t}\right)=z_{t}^{i}\left(k_{t}^{\alpha} \ell_{t}^{1-\alpha}\right)^{\phi}, \quad \phi, \alpha \in(0,1)
$$

Conforme Lucas (1978), o parâmetro ф, span of control, é o elemento que proporciona retornos decrescentes de escala, conferindo concavidade a função de produção, permitindo que haja lucro estritamente positivo em equilíbrio.

Caso decida empreender, o indivíduo pode financiar sua necessidade de capital de duas formas distintas: por meio de sua riqueza $a_{t}^{i}$ e, caso não seja suficiente, pode tomar empréstimo de um dos bancos para cobrir o restante necessário.

Caso decida utilizar a sua própria riqueza para financiar a sua necessidade de capital, o lucro da firma $\pi_{a}^{i}$ será dado por ${ }^{2}$ :

$$
\begin{array}{ll}
\pi_{a}^{i}=\operatorname{máx}_{\{k, \ell\}} & z^{i}\left(k^{\alpha} \ell^{1-\alpha}\right)^{\phi}-w \ell-(r+\delta) k \\
\text { sujeito a: } & k \leq a^{i}
\end{array}
$$

em que $\delta$ é a taxa de depreciação do capital e $r$ a taxa de retorno do ativo livre de risco desta economia ${ }^{3}$. Definimos também a escolha ótima de capital, $k_{a}(a, z, \theta, r, w)$, e trabalho, $\ell_{a}(a, z, \theta, r, w)$ como sendo a solução de (3.2).

Há um conjunto $\mathcal{J}$ de bancos dispostos ao longo da circunferência, sendo o número de bancos dado por $N_{\text {bancos }}=\operatorname{card}(\mathcal{J})$. Caso decida emprestar de um banco $j \in \mathcal{J}$, localizado na posição $\beta_{j}$, o indivíduo $i$ incorre em um custo de deslocamento $c\left(\theta^{i}, \beta_{j}\right)$ dado por:

$$
\mathrm{c}\left(\theta^{i}, \beta_{j}\right)=\tau \cdot \min \left\{\left|\theta^{i}-\beta_{j}\right|, 2 \pi-\left|\theta^{i}-\beta_{j}\right|\right\}
$$

em que $\tau$ é o custo por unidade de deslocamento. A Fig. 7 ilustra o cálculo deste custo adicional para o indivíduo $i$ para dois bancos distintos.

2 Para mais detalhes sobre a solução do problema da firma, ver Apêndice A.2

3 A rigor, as variáveis $\pi_{a}^{i}, k_{a}, \ell_{a}, w, r$ são dependentes do instante de tempo $t$. Omitimos a dependência temporal dessas variáveis para facilitar a notação e por estarmos interessados no estado estacionário do modelo. 
Figura 7 - Custo de deslocamento ao tomar empréstimo

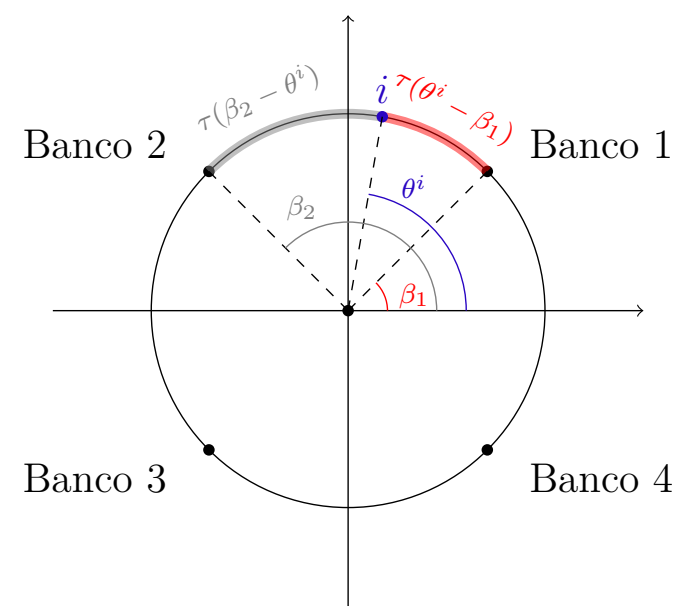

Fonte - Elaboração própria

Para cada $j \in \mathcal{J}$, o lucro da firma do indivíduo $i$ ao tomar empréstimo do banco $j$, $\pi_{e, j}^{i}$, será dado por ${ }^{4}$.

$$
\begin{aligned}
& \pi_{e, j}^{i}=\operatorname{máx}_{\{k, \ell\}} \quad z^{i}\left(k^{\alpha} \ell^{1-\alpha}\right)^{\phi}-w \ell-\left(r_{e, j}+\delta\right)\left(k-a^{i}\right)-a^{i}(r+\delta)-\mathrm{c}\left(\theta^{i}, \beta_{j}\right) \\
& \text { sujeito a: } \quad a^{i}<k \leq \lambda a^{i}
\end{aligned}
$$

em que $r_{e, j}$ é a taxa cobrada no empréstimo pelo banco $j$, formada por três componentes:

- $r$ : a taxa de captação de recursos dos bancos, dada pela taxa de retorno do ativo livre de risco.

- $\varepsilon$ : representa os custos administrativos, tributos e despesas com inadimplência.

- $s_{j}$ : estratégia escolhida pelo banco $j$, determinando sua margem financeira e lucro.

Desta forma, a taxa de empréstimo é dada por:

$$
r_{e, j}=r+s_{j}+\varepsilon
$$

Como em Evans e Jovanovic (1989), os indivíduos estão sujeitos a um limite de endividamento dado por $\lambda a^{i}$, com $\lambda \geq 1$. O parâmetro $\lambda$ mede o grau de fricções financeiras presentes no modelo. $\lambda=1$ corresponde ao caso extremo em que nenhum indivíduo tem acesso a crédito, ao passo que $\lambda=\infty$ corresponde à situação em que não há fricções no mercado de crédito.

4 Note que neste modelo, assim como em Aiyagari (1994), tudo se passa como se os bancos fossem os donos do capital e o alugassem para os empresários. Desta forma, o empresário não precisa acumular riqueza para pagar o principal emprestado, basta devolver ao banco o capital utilizado quando fechar a firma. 
A escolha por esse tipo de especificação se dá por dois motivos. O primeiro é que o limite máximo de endividamento de cada indivíduo é uma função linear da riqueza de cada um, fato previsto por vários modelos que abordam imperfeições no mercado de crédito (BUERA; SHIN, 2013). O segundo motivo é que tal restrição pode ser vista como consequência da existência de comprometimento limitado no cumprimento de contratos. De fato, Banerjee e Duflo (2010) apontam que uma das principais causas das ineficiências no mercado de crédito é a existência de "Moral Hazard". Inspirado em Madeira et al. (2018), supomos que os bancos restringem a quantidade máxima a ser emprestada de forma a evitar que os indivíduos tenham incentivos a não pagar pelo empréstimo. Se o indivíduo decidir não pagar pelo empréstimo, o banco pode confiscar uma fração da riqueza do dono da empresa, dada por $\eta a^{i}$. Desta forma, o banco decide o máximo a ser emprestado de acordo com a seguinte restrição de compatibilidade de incentivos:

$$
\begin{aligned}
z^{i}\left(k^{\alpha} \ell^{1-\alpha}\right)^{\phi}-w \ell-\left(r_{e, j}+\delta\right)\left(k-a^{i}\right)-a^{i}(r+\delta)-c\left(\theta^{i}, \beta_{j}\right) \geq \\
z^{i}\left(k^{\alpha} \ell^{1-\alpha}\right)^{\phi}-w \ell-\delta k-r a^{i}-c\left(\theta^{i}, \beta_{j}\right)-\eta a^{i}
\end{aligned}
$$

A expressão do lado esquerdo da desigualdade corresponde ao lucro da firma caso pague o empréstimo. A expressão do lado direito corresponde ao lucro da firma caso ela não pague o empréstimo e o banco confisque parte da riqueza do indivíduo. Isolando $k$ na expressão acima, obtemos:

$$
k \leq\left(1+\frac{\eta}{r_{e, j}}\right) a^{i}=\lambda a^{i}
$$

Definimos a escolha ótima de capital, $k_{e, j}\left(a, z, \theta, r, w, s_{j}\right)$, e trabalho, $\ell_{e, j}\left(a, z, \theta, r, w, s_{j}\right)$ como sendo a solução de (3.3).

Seja $j_{i}^{\prime}$ o banco que proporciona o maior lucro para a firma do indivíduo $i$ via empréstimo, isto é, $\pi_{e, j_{i}^{\prime}}^{i}=\operatorname{máx}\left\{\pi_{e, j}^{i}\right\}_{j \in \mathcal{J}}$. O lucro obtido pelo indivíduo $i$ caso decida empreender, $\pi^{i}$, será dado por $\pi^{i}=\operatorname{máx}\left\{\pi_{e, j_{i}^{\prime}}^{i} \pi_{a}^{i}\right\}$, isto é, o máximo entre o lucro obtido contratando empréstimo e aquele obtido utilizando apenas sua própria riqueza para financiar sua necessidade de capital. Definindo s como o vetor contendo as estratégias escolhidas pelos bancos, a solução do problema da firma fornece a demanda por trabalho, $\ell(a, z, \theta, r, w, \mathbf{s})$, e por capital, $k(a, z, \theta, r, w, \mathbf{s})$, sendo dadas indiretamente por:

$$
(k(\cdot), \ell(\cdot))= \begin{cases}\left(k_{e, j^{\prime}}(\cdot), \ell_{e, j^{\prime}}(\cdot)\right) & , \text { se } \pi_{e, j_{i}^{\prime}}^{i}>\pi_{a}^{i} \\ \left(k_{a}(\cdot), \ell_{a}(\cdot)\right) & , \text { se } \pi_{e, j_{i}^{\prime}}^{i} \leq \pi_{a}^{i}\end{cases}
$$

Ao solucionar o problema da firma, o indivíduo decide empreender se $\pi_{t}^{i}>w_{t}$, optando por trabalhar caso contrário. A sua renda, $y_{t}^{i}$, é dada então por ${ }^{5}$ :

$$
y_{t}^{i}=\operatorname{máx}\left\{\pi_{t}^{i}, w_{t}\right\}
$$

$\overline{5}$ Para mais detalhes sobre o problema da escolha ocupacional do indivíduo, ver Apêndice A.3 
A riqueza $a_{t}^{i}$ de cada indivíduo evolui da seguinte forma:

$$
\dot{a}_{t}^{i}=r_{t} a_{t}^{i}+y_{t}^{i}-c_{t}^{i}
$$

A Definição 3.1 descreve o problema do indivíduo.

Definição 3.1 (Problema do indivíduo). Uma trajetória de consumo $\left\{c_{t}^{i}\right\}_{t \in[0, \infty)}$ é solução do problema do indivíduo se ela maximiza a utilidade esperada ao longo do tempo, descontada pelo fator de desconto intertemporal $\rho$, sujeito as Eqs. (3.1) e (3.7), isto é:

$$
\begin{aligned}
& \underset{\left\{c_{t}^{i}\right\}_{t \in[0, \infty)}}{\operatorname{máx}} \mathbb{E}_{0}\left[\int_{0}^{\infty} e^{-\rho t} u\left(c_{t}^{i}\right) \mathrm{d} t\right] \\
& \text { sujeito a: }\left\{\begin{array}{l}
\dot{a}_{t}^{i}=r_{t} a_{t}^{i}+y_{t}^{i}-c_{t}^{i} \\
\mathrm{~d} \ln z_{t}^{i}=-\varphi \ln z_{t}^{i} \mathrm{~d} t+\zeta \mathrm{d} W_{t} \\
a_{t}^{i} \geq 0
\end{array}\right.
\end{aligned}
$$

Em cada instante $t$, a sequência de eventos e decisões do indivíduo é dada conforme Fig. 8:

Figura 8 - Sequência de eventos

Ação 0

Ação 1

Ação 2

- Realização do choque de produtividade
- Indivíduo observa o choque

- Decide se empreende ou se trabalha determinando sua renda $y_{t}^{i}$
- Indivíduo determina sequência de consumo e poupança conforme Def 3.1

Fonte - Elaboração própria

A solução do problema do indivíduo nos fornece uma policy function $p(a, z, \theta)$ com a decisão de poupança do indivíduo e uma função $g(a, z, \theta)$ com a distribuição conjunta da riqueza, produtividade e posição dos indivíduos desta economia.

A demanda por empréstimo do banco $j$ é dada por:

$$
d_{j}\left(s_{j}, \mathbf{s}_{-j}\right)=\int_{0}^{2 \pi} \int_{\underline{z}}^{\bar{z}} \int_{\underline{a}}^{\bar{a}} \operatorname{máx}\{k(\cdot)-a, 0\} g(a, z, \theta) \mathbb{1}_{\left\{\pi^{i}>w\right\}} \mathbb{1}_{\left\{j=j_{i}^{\prime}\right\}} \mathrm{d} a \mathrm{~d} z \mathrm{~d} \theta
$$

em que $\mathbf{s}_{-j}$ corresponde a um vetor formado pelas estratégias escolhidas pelos bancos do conjunto $\mathcal{J}$ com exceção do próprio banco $j$. A função indicadora $\mathbb{1}_{\left\{\pi^{i}>w\right\}}$ assume valor 1 quando o indivíduo $i$ decide empreender, assumindo valor 0 caso contrário. A função indicadora $\mathbb{1}_{\left\{j=j_{i}^{\prime}\right\}}$ assume valor 1 quando o banco $j$ é aquele que maximiza o lucro via 
empréstimo da firma do indivíduo $i$, assumindo valor 0 caso contrário. O correspondente lucro do banco $j$ é dado por:

$$
\pi_{j}^{\text {banco }}\left(s_{j}, \mathbf{s}_{-j}\right)=d_{j}\left(s_{j}, \mathbf{s}_{-j}\right) \cdot s_{j}
$$

Cada banco define sua estratégia $s_{j}$ de forma a maximizar seu lucro, tomando como dado as estratégias dos demais bancos. Um vetor $\hat{\mathbf{s}}$ é solução do problema dos bancos se ele satisfaz a Definição 3.2.

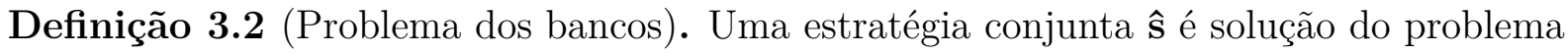
dos bancos se ela for um equilíbrio de Nash do jogo não cooperativo praticado pelos bancos, isto é: para todo banco $j \in \mathcal{J}$ temos que $\pi_{j}^{\text {banco }}\left(\hat{s_{j}}, \hat{\mathbf{s}_{-j}}\right) \geq \pi_{j}^{\text {banco }}\left(\hat{s_{j}}, \hat{\mathbf{s}_{-j}}\right), \forall s_{j} \in \mathbb{R}_{+}$

A taxa de retorno do ativo livre de risco $r$ e o salário $w$ são obtidos das condições de market clearing. A condição de market clearing no mercado de trabalho é dada por:

$$
\int_{0}^{2 \pi} \int_{\underline{z}}^{\bar{z}} \int_{\underline{a}}^{\bar{a}} g(a, z, \theta) \mathbb{1}_{\left\{\pi^{i} \leq w\right\}} \mathrm{d} a \mathrm{~d} z \mathrm{~d} \theta=\int_{0}^{2 \pi} \int_{\underline{z}}^{\bar{z}} \int_{\underline{a}}^{\bar{a}} \ell(\cdot) g(a, z, \theta) \mathbb{1}_{\left\{\pi^{i}>w\right\}} \mathrm{d} a \mathrm{~d} z \mathrm{~d} \theta
$$

O termo ao lado esquerdo da igualdade corresponde à oferta de trabalho por parte dos indivíduos que decidem trabalhar. O lado direito corresponde à demanda por trabalho dos indivíduos que decidem empreender, contratando capital e trabalho.

A condição de market clearing no mercado de crédito é dada por:

$$
\begin{aligned}
\int_{0}^{2 \pi} \int_{\underline{z}}^{\bar{z}} \int_{\underline{a}}^{\bar{a}}(k(\cdot)-a) g(a, z, \theta) \mathbb{1}_{\left\{\pi^{i}>w\right\}} \mathbb{1}_{\left\{\pi_{e, j_{i}^{i}}>\pi_{a}^{i}\right\}} \mathrm{d} a \mathrm{~d} z \mathrm{~d} \theta= \\
(1-\chi)\left[\int_{0}^{2 \pi} \int_{\underline{z}}^{\bar{z}} \int_{\underline{a}}^{\bar{a}} a g(a, z, \theta) \mathbb{1}_{\left\{\pi^{i} \leq w\right\}} \mathrm{d} a \mathrm{~d} z \mathrm{~d} \theta\right. \\
\left.+\int_{0}^{2 \pi} \int_{\underline{z}}^{\bar{z}} \int_{\underline{a}}^{\bar{a}}(a-k(\cdot)) g(a, z, \theta) \mathbb{1}_{\left\{\pi^{i}>w\right\}} \mathbb{1}_{\left\{\pi_{e, j_{i}^{\prime}} \leq \pi_{a}^{i}\right\}} \mathrm{d} a \mathrm{~d} z \mathrm{~d} \theta\right]
\end{aligned}
$$

O termo ao lado esquerdo da igualdade corresponde à demanda por crédito por parte dos indivíduos que decidem tomar empréstimo. O lado direito da igualdade corresponde à oferta de crédito disponível na economia, composta pela riqueza dos indivíduos que decidem trabalhar (primeiro termo) e pela riqueza líquida de investimento em capital dos indivíduos que decidem empreender e financiar sua necessidade de capital com a própria riqueza (segundo termo). O parâmetro $\chi$ corresponde a alíquota de depósito compulsório, de modo que há uma fração $\chi$ do total poupado não disponível para os bancos emprestarem.

O interesse é determinar o equilíbrio em estado estacionário do modelo, conforme a Definição 3.3. 
Definição 3.3 (Equilíbrio de estado estacionário do modelo). Um equilíbrio de estado estacionário desta economia é caracterizado por uma taxa de retorno do ativo livre de risco, $r$, um salário, $w$, um vetor de estratégias dos bancos, $\hat{\mathbf{s}}$, uma função demanda por trabalho, $\ell(a, z, \theta, r, w, \mathbf{s})$, e por capital, $k(a, z, \theta, r, w, \mathbf{s})$, uma policy function $p(a, z, \theta) \mathrm{e}$ uma função de distribuição conjunta de riqueza, produtividade e posição de indivíduos $g(a, z, \theta)$ tais que:

1. Dados $r, w$ e $\hat{\mathbf{s}}$, as demandas $\ell(a, z, \theta, r, w, \hat{\mathbf{s}})$ e $k(a, z, \theta, r, w, \hat{\mathbf{s}})$ são soluções do problema das firmas, conforme Eq. (3.5).

2. A policy function $p(a, z, \theta)$ e a função densidade de tipos de indivíduos $g(a, z, \theta)$ satisfazem as condições impostas pelo problema do indivíduo e $g(a, z, \theta)$ é invariante no tempo.

3. A taxa de retorno do ativo livre de risco $r$ e o salário $w$ equilibram os mercados de crédito e de trabalho, conforme Eqs. (3.11) e (3.12).

4. O vetor $\hat{\mathbf{s}}$ satisfaz a Definição 3.2.

\subsection{Solução do Modelo}

A solução numérica do modelo é baseada na estrutura proposta em Achdou et al. (2021). Tal estrutura reduziu significativamente o tempo de processamento do algoritmo utilizado na solução do problema do indivíduo, tornando factível a solução de problemas com mais dimensões de heterogeneidade, como neste caso.

O Apêndice B.1 traz mais detalhes do método utilizado para obter a solução do problema do indivíduo. O Apêndice B.2 detalha o método empregado para encontrar o vetor de preços que satisfaz as condições de market clearing. O método empregado na solução do problema dos bancos é detalhado no Apêndice B.3. 


\section{Calibração}

A calibração do modelo será dividida em duas partes. Em uma primeira etapa, parte dos parâmetros serão escolhidos com base nos valores usualmente utilizados na literatura. Posteriormente, o restante dos parâmetros será calibrado de forma a replicar no modelo alguns dos momentos dos dados brasileiros.

O ponto de partida é a definição dos grids utilizados. A Tabela 1 traz os parâmetros adotados para os grids. Há um inevitável tradeoff entre precisão dos resultados e tempo de processamento do algoritmo. Desta forma, adotou-se para cada um dos grids um número de pontos que permitisse a solução do modelo em um tempo adequado com o menor comprometimento possível da precisão dos resultados. O limite superior do grid de riqueza $(\bar{a})$ foi escolhido de forma que a massa de indivíduos cuja riqueza é $\bar{a}$ seja desprezível. Com relação ao grid de produtividade, $\underline{z}$ e $\bar{z}$ foram escolhidos de forma a não cortar parte significativa das caudas superior e inferior da distribuição estacionária de produtividade gerada pelo processo de difusão ${ }^{1}$. Para as estratégias dos bancos, o grid utilizado tem espaçamento de $0.1 \%$ entre pontos. Porém, o número de pontos, bem como o primeiro e último ponto, varia de acordo com o cenário simulado.

Tabela 1 - Parâmetros dos grids

\begin{tabular}{llll}
\hline \multirow{2}{*}{ Variável } & \multicolumn{3}{c}{ Grid } \\
\cline { 2 - 4 } & Riqueza & Produtividade & Posição \\
\hline Limite inferior & $\underline{a}=0$ & $\underline{z}=0.14$ & $\underline{\theta}=0$ \\
Limite superior & $\bar{a}=1000$ & $\bar{z}=5.13$ & $\bar{\theta}=2 \pi$ \\
Número de pontos & $N_{a}=1000$ & $N_{z}=50$ & $N_{\theta}=72$ \\
Distância entre pontos consecutivos & $\Delta a=1.00$ & $\Delta z=0.10$ & $\Delta \theta=0.09$ \\
\hline Fonte: Elaboração própria & & &
\end{tabular}

O modelo contará com quatro bancos, localizado nas posições $\beta_{1}=0, \beta_{2}=\frac{\pi}{2}$, $\beta_{3}=\pi$, e $\beta_{4}=\frac{3 \pi}{2}$, conforme Fig. 9. A escolha do número de bancos e posições se dá por razões computacionais. Como há simetria no modelo, há uma redução considerável no tempo levado para solucioná-lo, facilitando o processo de calibração.

1 Em estado estacionário, $z$ segue uma distribuição lognormal com média 0 e variância $\frac{\zeta^{2}}{2 \varphi}$. Escolhemos $\underline{z}$ e $\bar{z}$ de forma que $\operatorname{Prob}(z \leq \underline{z})=\operatorname{Prob}(z \geq \bar{z})=0.01 \%$ 
Figura 9 - Disposição dos bancos

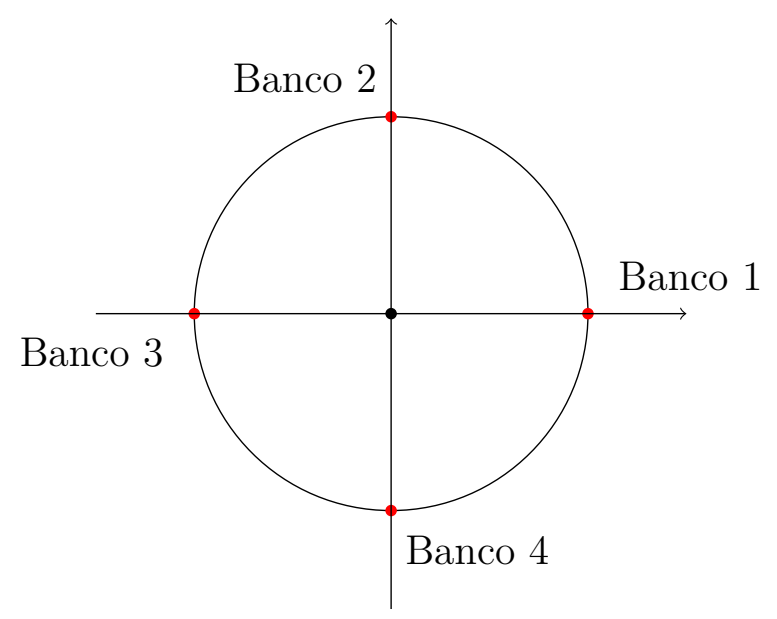

Fonte - Elaboração própria

O modelo utilizado possui onze parâmetros, dos quais dois serão fixados previamente. O coeficiente de aversão relativa ao risco é ajustado para $\gamma=1.5$, em linha com outros trabalhos desenvolvidos para o Brasil (por exemplo, Cavalcanti et al. (2021)). A taxa de depreciação do capital utilizada, $\delta=0.04$, é baseada em Madeira et al. (2018).

Dos parâmetros remanescentes, três são retirados diretamente dos dados. A alíquota de depósito compulsório utilizada é de $\chi=23 \%$, com base na alíquota efetiva total calculada pelo Banco Central para o ano de $2018^{2}$. Para o share de capital na função de produção, adotamos $\alpha=0.40$, com base em Gollin (2002) e valor próximo ao encontrado para o Brasil na Penn World Table 10.0 (Feenstra, Inklaar e Timmer (2015)). Por fim, a parcela do spread formada por custos administrativos, inadimplência e tributos, dada por $\epsilon$, é estimada de acordo com Banco Central do Brasil (2019). Como detalhado no Capítulo 2, em 2018, o Banco Central estimou que $82 \%$ do spread era composto por despesas administrativas, inadimplência e tributos. Neste mesmo ano, o spread médio para pessoas jurídicas foi de $9.1 \%$. Logo, adotamos $\epsilon=7.4 \%$.

Os seis parâmetros remanescentes serão calibrados para ajustar o modelo a oito momentos observados nos dados para o Brasil, majoritariamente para o ano de 2018, a saber: fração de empresários, fração de micro, pequenas, médias e grandes firmas, fração de firmas sem acesso ao mercado de crédito, total de crédito para empresas como fração do PIB e taxa de retorno livre de risco.

Para estimar a fração de empresários na população, utilizamos os dados da PNAD de 2018 e calculamos a razão entre o número de pessoas classificadas como empregadoras

2 A rigor, a alíquota de recolhimento de compulsórios varia conforme origem dos recursos (recursos a vista, a prazo e poupança) e o patrimônio de referência de cada instituição financeira. Como o modelo utilizado não permite fazer esta distinção entre origem de recursos e instituições financeiras, adotamos a alíquota efetiva total, composta pela razão entre o total de recolhimentos compulsórios e o valor total sujeito a recolhimento. Para mais detalhes, ver Banco Central do Brasil (2019). 
ou trabalhadoras por conta própria e o número total de pessoas.

A distribuição de tamanho de firmas é estimada utilizando dados da RAIS para 2018. Para classificar as empresas com relação ao porte, seguimos o critério do SEBRAE para o setor de comércio e serviços ${ }^{3}$, que atribui o porte da empresa de acordo com o número de funcionários: micro até 9 funcionários, pequenas de 10 a 49 funcionários, médias de 50 a 99 funcionários e grandes: acima de 100 funcionários.

O percentual de firmas sem acesso ao mercado de crédito segue o reportado em Madeira et al. (2018) para o ano de 2012. Neste trabalho, combinando dados da RAIS e do Sistema de Informações de Crédito (SCR) do Banco Central do Brasil, os autores estimam que $49.2 \%$ das firmas não tinham acesso ao mercado de crédito e 1.8\% tinha acesso apenas a crédito direcionado. Como não contemplamos direcionamento de crédito neste modelo, utilizamos o valor de $51 \%$ como estimativa de firmas sem acesso a crédito na calibração ${ }^{4}$.

Sobre o montante de crédito destinado a empresas, utilizamos a média do saldo de crédito ampliado concedido a empresas em relação ao PIB para o ano de 2018, conforme disponível no Sistema Gerenciador de Séries Temporais do Banco Central ${ }^{5}$.

O último momento utilizado na calibração é a taxa de retorno do ativo livre de risco dessa economia. Para estimar esta taxa, seguimos procedimento similar ao de Cavalcanti et al. (2021): calculamos a diferença entre a taxa SELIC e o IPCA mês a mês, tomamos a média para o período de 2009-2018 e anualizamos, chegando a uma taxa de aproximadamente $4.1 \%$. Por fim, subtraímos uma estimativa de prêmio de risco de default para o Brasil no mesmo período ${ }^{6}$, o que nos dá uma taxa de aproximadamente $2 \%$.

Embora a calibração dos seis parâmetros aconteça de forma conjunta, o racional por trás do processo será explicado na sequência. A taxa de desconto intertemporal $\rho$ é ajustada para obtermos a taxa de retorno do ativo livre de risco desejada. Os dois parâmetros do processo de difusão $(\varphi$ e $\zeta)$ e o span of control $(\phi)$ da função de produção são determinados visando reproduzir os quatro momentos da distribuição de tamanho de firmas e a fração de empresários na economia. O parâmetro $\eta$, que afeta o máximo que cada indivíduo pode tomar emprestado, é fixado de forma a ajustar o saldo de crédito, em relação ao PIB, gerado pelo modelo. O custo de deslocamento $\tau$ é determinado de forma a garantir que a fração de empresas com acesso a crédito no modelo se ajuste aos dados brasileiros. A Tabela 2 traz os valores adotados para cada parâmetro do modelo bem como sua fonte. A Tabela 3 compara os momentos gerados pelo modelo após a calibração com os respectivos momentos dos dados brasileiros.

3 Segundo o Cadastro Geral de Empresas do IBGE, 84\% das empresas no Brasil pertenciam ao setor de comércio e serviços em 2018.

4 Do restante das firmas, $32.7 \%$ utilizam apenas crédito livre e $16.3 \%$ utilizam tanto crédito livre como direcionado.

5 Disponível aqui.

6 Utilizamos a média do CDS Brasil para o período. 
Tabela 2 - Parâmetros do modelo

\begin{tabular}{llll}
\hline Parâmetro & Descrição & Valor & Fonte \\
\hline$\gamma$ & Coeficiente de aversão ao risco relativo CRRA & 1.5 & Cavalcanti et al. (2021) \\
$\rho$ & Taxa de desconto & 0.122 & Calibração \\
$\varphi$ & Parâmetro processo de difusão & 0.06 & Calibração \\
$\zeta$ & Parâmetro processo de difusão & 0.1834 & Calibração \\
$\delta$ & Taxa de depreciação & 0.04 & Madeira et al. (2018) \\
$\alpha$ & Share de capital Cobb-Douglas & 0.40 & Gollin (2002) \\
$\phi$ & Span of Control & 0.74 & Calibração \\
$\eta$ & Restrição de empréstimo & 0.123 & Calibração \\
$\tau$ & Custo de deslocamento & 0.63 & Calibração \\
$\epsilon$ & Parcela do spread correspondente a custos e tributos & $7.4 \%$ & Banco Central do Brasil (2019) \\
$\chi$ & Alíquota depósito compulsório & $23 \%$ & Banco Central do Brasil (2019) \\
\hline
\end{tabular}

Fonte: Elaboração própria

Tabela 3 - Ajuste do modelo aos dados

\begin{tabular}{lll}
\hline Momento & Modelo & Dados \\
\hline Fração de empresários & $13.8 \%$ & $13.3 \%$ \\
Fração de micro firmas & $81.4 \%$ & $81.5 \%$ \\
Fração de firmas pequenas & $18.0 \%$ & $15.4 \%$ \\
Fração de firmas médias & $0.6 \%$ & $1.6 \%$ \\
Fração de firmas grandes & $<0.01 \%$ & $1.5 \%$ \\
Fração de firmas sem acesso ao mercado de crédito & $51.0 \%$ & $51.0 \%$ \\
Crédito/PIB & $44.2 \%$ & $44.1 \%$ \\
Taxa de retorno do ativo livre de risco $(r)$ & $2.0 \%$ & $2.0 \%$ \\
\hline
\end{tabular}

Fonte: Elaboração própria

Como pode ser visto, o modelo se ajusta bem aos dados brasileiros, mas não de forma perfeita, ainda que o número de parâmetros calibrados (6) seja menor que o de momentos (8). Vale ressaltar que o modelo não é capaz de replicar a cauda superior pesada de firmas que encontramos no país, como pode ser observado pelo baixo percentual de firmas médias e grandes gerado pelo modelo. ${ }^{7}$

7 Uma possível explicação é a elevada presença de créditos subsidiados no país, que não é incorporado neste modelo. A fração de firmas que tem acesso a crédito direcionado é substancialmente maior para empresas grandes do que para pequenas (MADEIRA et al., 2018). 


\section{Resultados}

Com o modelo calibrado para os dados brasileiros, analisamos, primeiramente, alguns dos resultados de estado estacionário encontrados e que não foram discutidos na etapa de calibração. Posteriormente, procuramos entender quais os efeitos do custo de deslocamento em algumas das características dos indivíduos, como escolha ocupacional, demanda por empréstimos, distribuição de tamanho de firmas e desigualdade.

A Tabela 4 apresenta os resultados de estado estacionário do modelo para algumas variáveis relevantes. Como salientado na seção anterior, o modelo foi calibrado para o caso em que há simetria na disposição dos bancos, de forma que o spread resultante em equilíbrio é o mesmo para os quatro bancos. O equilíbrio de Nash do jogo dos bancos encontrado é $1.1 \%$. Combinando esta taxa $\operatorname{com} \varepsilon$, que representa custos administrativos, inadimplência e tributos, o spread total obtido é de $8.5 \%$, valor próximo ao spread médio das operações com pessoas jurídicas em 2018, de $9.1 \%$.

Como salientado na Capítulo 4, o modelo não é capaz de reproduzir a cauda pesada da distribuição de tamanho de firmas, como ficou evidente pela baixa fração de firmas grandes no modelo. Tal dificuldade de ajuste fica evidente quando comparamos o tamanho médio das firmas gerado pelo modelo (6.22) com o respectivo valor encontrado nos dados brasileiros para 2018 (13.5), embora a mediana do tamanho das firmas do modelo (3.28) seja bastante próxima aos dados (3).

O modelo produz um índice de Gini, calculado com base na renda dos indivíduos, inferior ao calculado pelo IBGE em 2018, de 0.54. A principal explicação para esta diferença é que, neste modelo, embora tenhamos uma distribuição de lucro de firmas, derivada da distribuição de produtividade, todos os agentes que decidem trabalhar recebem o mesmo salário, reduzindo consideravelmente parte da desigualdade.

O valor encontrado para o parâmetro $\lambda$ foi de 2.17. Assim, cada indivíduo pode tomar um empréstimo de, no máximo, 2.17 vezes o valor da sua riqueza. Tal valor é próximo ao encontrado na literatura e ao estimado para o Brasil, de 2.33. (MADEIRA, 2008; SANTOS, 2016) 
Tabela 4 - Resultados de estado estacionário

\begin{tabular}{cll}
\hline \multicolumn{2}{l}{ Variável } & Valor \\
\hline- & Gini renda & 0.387 \\
$w$ & Salário & 1.20 \\
$\lambda$ & Restrição de empréstimo & 2.17 \\
$\hat{s}_{j}$ & Equilíbrio de Nash dos bancos & $1.1 \%$ \\
$r_{e, j}$ & Taxa de empréstimo & $10.5 \%$ \\
- & Mediana tamanho firmas & 3.28 \\
- & Média tamanho firmas & 6.22 \\
\hline
\end{tabular}

Fonte: Elaboração própria

A Fig. 10 mostra como a posição do indivíduo afeta algumas das suas características. Note que o grid de produtividade utilizado contém 72 pontos, de forma que a distância entre dois pontos consecutivos é $5^{\circ}$. Cada banco ocupa a posição $0^{\circ}, 90^{\circ}, 180^{\circ}$ e $270^{\circ}$ e, dada a simetria do modelo, os resultados são simétricos em relação ao ângulo de $45^{\circ}$, como pode ser visto na Fig. 10d.

Figura 10 - Características dos indivíduos e firmas por posição

(a) Porte das firmas
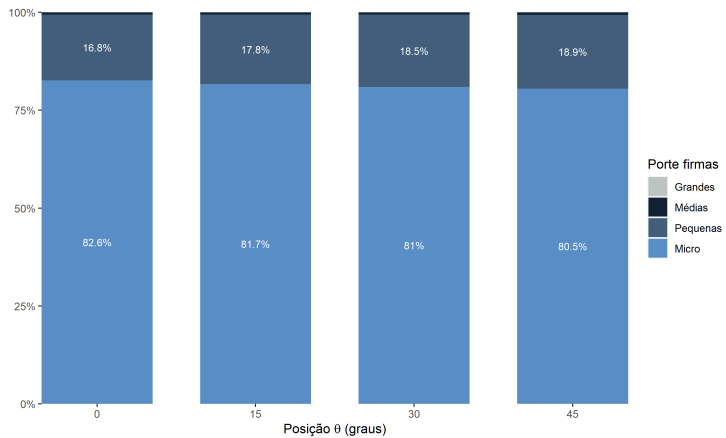

(c) \% indivíduos donos de empresas

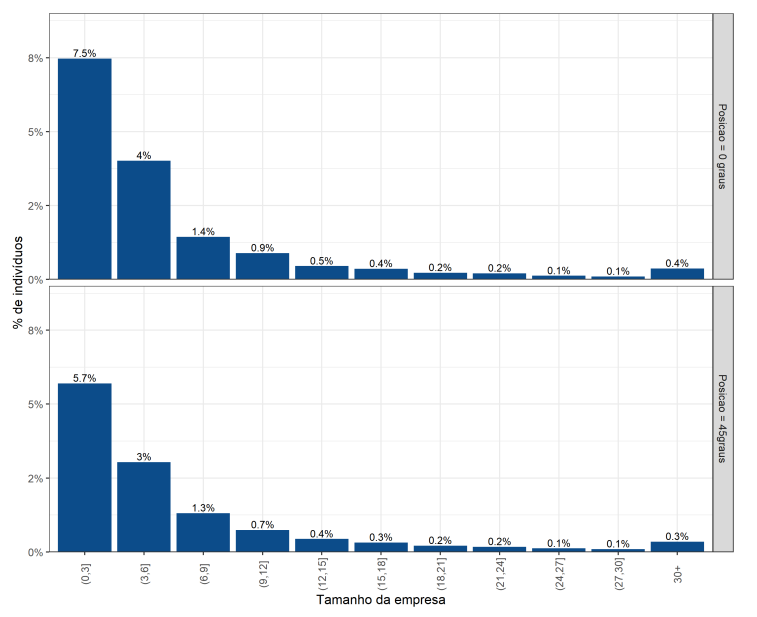

(b) Escolha ocupacional e financiamento
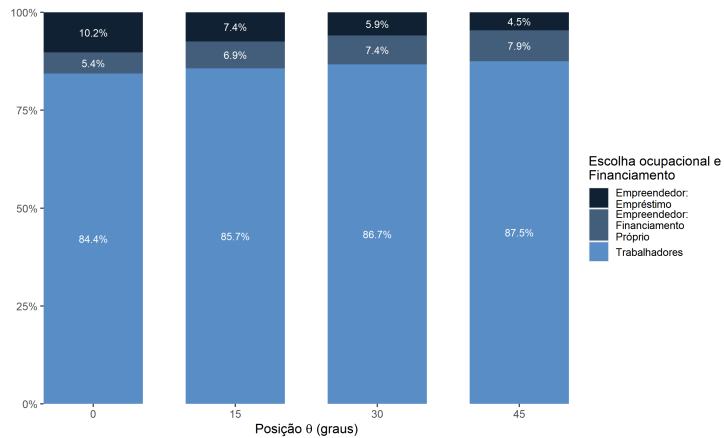

(d) Riqueza, bem-estar, lucro, desigualdade e demanda líquida por empréstimos
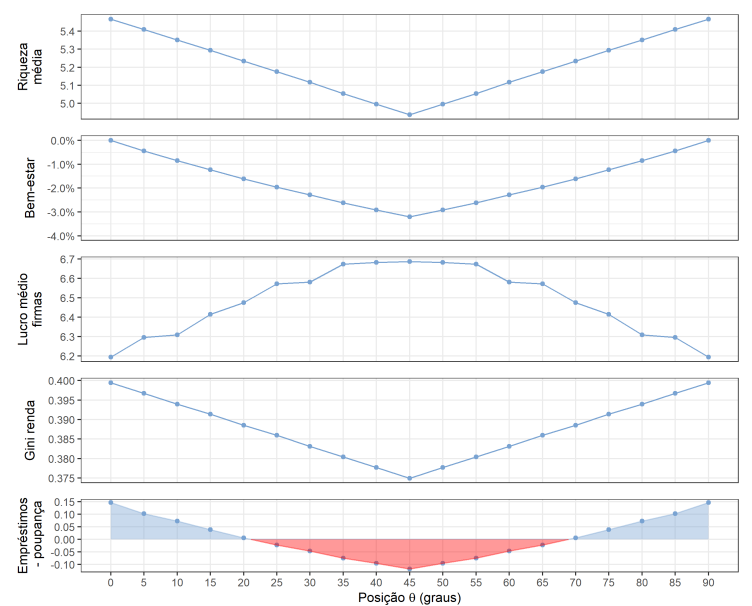

Fonte - Elaboração própria 
Quanto mais distantes os indivíduos estão de um dos bancos, maior o custo de deslocamento que arcam para tomar empréstimo. Há duas principais consequências deste fato para as características das firmas. A primeira é a redução na fração de empresários com o aumento de $\theta$. De fato, ao analisar a Fig. 10b, nota-se que $15.6 \%$ dos indivíduos localizados na posição $\theta=0^{\circ}$ decidem ser empresários, enquanto para $\theta=45^{\circ}$, a fração de empresários cai para $12.4 \%$.

Esta queda no número de empresários com o aumento de $\theta$ pode ser entendida analisando os indivíduos cuja riqueza, a, e produtividade, z, os deixam indiferentes entre emprestar ou trabalhar quando localizados na posição $\theta=0^{\circ}{ }^{1}$. Considerando esses pares de riqueza e produtividade, um aumento em $\theta$ reduz o lucro da firma destes indivíduos, que passam a ter renda superior trabalhando, reduzindo, assim, a fração de empresários.

Para entender quais são as firmas mais afetadas pelo custo de deslocamento, a Fig. 10c mostra o percentual de indivíduos donos de firmas em função do tamanho delas (número de funcionários), para os indivíduos localizados em $\theta=0^{\circ}$ e $\theta=45^{\circ}$. Como mencionado anteriormente, o número de empresários cai de $15.6 \%$, em $\theta=0^{\circ}$, para $12.4 \%$, em $\theta=45^{\circ}$. O percentual de indivíduos dono de firmas com até 3 funcionários é de $7.5 \%$ para $\theta=0^{\circ}$ e de $5.7 \%$ para $\theta=45^{\circ}$. Logo, da diferença de 3.2 pontos percentuais no número de empresários, 1.8 corresponde a indivíduos donos de firmas com até 3 funcionários. A análise da Fig. 10c permite concluir que as microempresas são as mais afetadas pelo custo de deslocamento. De fato, a queda no número de indivíduos donos de microempresas é de 2.9 pontos percentuais. Note ainda que o impacto no número de indivíduos donos de firmas com mais de 18 funcionários é praticamente nulo. Como consequência, a fração de micro firmas decai com o aumento de $\theta$, como pode ser visto na Fig. 10a.

A segunda consequência do custo de deslocamento é a alteração da forma de financiamento de capital dos indivíduos. À medida que $\theta$ aumenta, um número menor de empresários decide tomar empréstimo, passando a financiar sua necessidade de capital apenas com sua própria riqueza. Analisando a Fig. 10b, cerca de $2 / 3$ dos empresários localizados em $\theta=0^{\circ}$ tomam empréstimos, ao passo que pouco menos de $40 \%$ dos empresários localizados em $\theta=45^{\circ}$ o fazem ${ }^{2}$.

O lucro total de cada uma das empresas decresce com o aumento da distância entre os empresários e dos bancos. Apesar disso, o lucro médio por empresa aumenta com $\theta$, conforme Fig. 10d. A razão para isso é que há uma parcela de empresas pequenas, com lucros pequenos, que deixam de existir, de forma que, na média, temos empresas maiores com lucro maiores.

1 Tais indivíduos estão localizados ao longo das curvas 2 e 3 da Fig. 13 no Apêndice B.1.

2 Para entender este efeito, basta repetir o raciocínio do parágrafo anterior para os indivíduos cuja riqueza e produtividade os deixam indiferentes entre tomar empréstimo e utilizar apenas sua riqueza para financiar capital quando localizados na posição $\theta=0^{\circ}$. Tais indivíduos estão localizados sobre a curva que separa as duas regiões em cinza da Fig. 13 do Apêndice B.1. 
Dada a redução no lucro das empresas e na fração de empresários, a renda dos indivíduos decai com $\theta$. Isto se traduz tanto em uma piora no nível de bem-estar, pela redução do consumo, como também em redução da riqueza dos indivíduos. ${ }^{3}$ Há ainda uma redução na desigualdade de renda dos indivíduos com o aumento da distância, consequência da redução na renda e aumento na fração de indivíduos que decidem trabalhar ${ }^{4}$.

Por fim, é interessante notar o comportamento do total emprestado e poupado pelos indivíduos em função da posição de cada um deles. O último gráfico da Fig. 10d mostra a diferença entre o total emprestado e o total poupado em função da posição dos indivíduos. Percebe-se que os indivíduos mais afastados dos bancos acabam financiando parte da necessidade de capital dos indivíduos mais "sortudos" que estão mais próximos aos bancos. Estes indivíduos mais "sortudos" acabam se beneficiando, em parte, da existência do custo de deslocamento. De fato, na ausência deste custo e mantendo o spread cobrado pelos bancos, os indivíduos localizados na posição $\theta=0^{\circ}$ pagariam uma taxa de empréstimo de $10.7 \%$ ao invés de $10.5 \%$, devido ao aumento na taxa de retorno do ativo livre de risco necessário para equilibrar os mercados.

A Tabela 5 apresenta os principais resultados dos exercícios contrafactuais realizados. A coluna (1) corresponde ao cenário base, com os parâmetros iguais aos obtidos na etapa de calibração. Para facilitar a comparação entre cenários, normalizamos, em relação ao cenário base, as variáveis PIB, crédito, salário e lucro dos bancos.

3 Para mensurar o impacto em bem-estar, procedemos da seguinte forma: calculamos a utilidade média dos indivíduos localizados em cada uma das posições. Medimos, então, qual a variação no consumo de cada indivíduo localizado na posição $\theta=0^{\circ}$ que levaria a mesma utilidade média observada em cada uma das demais posições. Assim, para atingir a utilidade média dos indivíduos localizados em $\theta=45^{\circ}$, o consumo dos indivíduos localizados em $\theta=0^{\circ}$ deveria ser reduzido em aproximadamente $3 \%$. Seguimos este mesmo procedimento nos demais cálculos de impacto em bem-estar desta seção.

4 Note que os indivíduos que decidem trabalhar recebem o mesmo salário $w$. 
Tabela 5 - Resultados contrafactuais

\begin{tabular}{|c|c|c|c|c|c|c|}
\hline & \multirow{2}{*}{ Variável } & \multirow{2}{*}{$\frac{\text { Base }}{(1)}$} & \multirow{2}{*}{$\frac{s_{j}=0}{(2)}$} & \multicolumn{3}{|c|}{ Efeito custo deslocamento } \\
\hline & & & & $(3)$ & $(4)^{\mathrm{a}}$ & (5) \\
\hline \multirow{9}{*}{ Agregados } & Bem-estar & - & $1.2 \%$ & $1.6 \%$ & $2.8 \%$ & $3.9 \%$ \\
\hline & Gini renda & 0.387 & 0.389 & 0.386 & 0.385 & 0.384 \\
\hline & PIB & 1.000 & 1.012 & 1.010 & 1.014 & 1.018 \\
\hline & Crédito & 1.000 & 1.161 & 1.103 & 1.161 & 1.211 \\
\hline & Crédito/PIB & $44.2 \%$ & $50.7 \%$ & $48.3 \%$ & $50.6 \%$ & $52.6 \%$ \\
\hline & Tx. retorno livre de risco & $2.0 \%$ & $2.4 \%$ & $2.2 \%$ & $2.5 \%$ & $2.8 \%$ \\
\hline & Salário & 1.000 & 1.009 & 1.011 & 1.020 & 1.027 \\
\hline & Empresários & $13.8 \%$ & $13.5 \%$ & $14.0 \%$ & $14.3 \%$ & $14.6 \%$ \\
\hline & TFP & - & $0.6 \%$ & $1.0 \%$ & $1.7 \%$ & $2.2 \%$ \\
\hline \multirow{5}{*}{ Firmas } & Micro & $81.4 \%$ & $80.7 \%$ & $82.0 \%$ & $82.7 \%$ & $83.3 \%$ \\
\hline & Pequenas & $18.0 \%$ & $18.7 \%$ & $17.4 \%$ & $16.8 \%$ & $16.3 \%$ \\
\hline & Médias & $0.6 \%$ & $0.6 \%$ & $0.5 \%$ & $0.5 \%$ & $0.4 \%$ \\
\hline & Grandes & $<0.01 \%$ & $<0.01 \%$ & $<0.01 \%$ & $<0.01 \%$ & $<0.01 \%$ \\
\hline & $\mathrm{S} /$ acesso à crédito & $51.0 \%$ & $47.1 \%$ & $43.2 \%$ & $39.5 \%$ & $32.0 \%$ \\
\hline \multirow{8}{*}{ Bancos } & Estratégia Eq. Nash banco 1 & $1.1 \%$ & $0.0 \%$ & $0.7 \%$ & $0.3 \%$ & $0.0 \%$ \\
\hline & Estratégia Eq. Nash banco 2 & $1.1 \%$ & $0.0 \%$ & $0.7 \%$ & $0.3 \%$ & $0.0 \%$ \\
\hline & Estratégia Eq. Nash banco 3 & $1.1 \%$ & $0.0 \%$ & $0.7 \%$ & $0.3 \%$ & $0.0 \%$ \\
\hline & Estratégia Eq. Nash banco 4 & $1.1 \%$ & $0.0 \%$ & $0.7 \%$ & $0.3 \%$ & $0.0 \%$ \\
\hline & Lucro banco 1 & 1.00 & 0.00 & 0.70 & 0.32 & 0.00 \\
\hline & Lucro banco 2 & 1.00 & 0.00 & 0.70 & 0.32 & 0.00 \\
\hline & Lucro banco 3 & 1.00 & 0.00 & 0.70 & 0.32 & 0.00 \\
\hline & Lucro banco 4 & 1.00 & 0.00 & 0.70 & 0.32 & 0.00 \\
\hline
\end{tabular}

Coluna (1) corresponde ao cenário base, com os parâmetros calibrados conforme Tabela 2. Coluna (2): $\tau=0.63$, mas spread dos bancos é fixado em 0. Coluna (3): $\tau=\frac{0.63}{2}$. Coluna (4): $\tau=\frac{0.63}{4}$. Coluna (5): $\tau=0$.

a Neste cenário encontramos dois equilíbrios de Nash. Além do reportado na tabela, a estratégia $s_{j}=0.4 \%$ também é um equilíbrio de Nash do jogo dos bancos. A existência de dois equilíbrios possivelmente é explicada pelo fato de utilizarmos um grid para as estratégias com espaçamento de $0.1 \%$ e o "verdadeiro" equilíbrio, aquele em que o conjunto de estratégias dos bancos é o próprio $\mathbb{R}_{+}$e não um conjunto discreto, estar entre $0.3 \%$ e $0.4 \%$.

A coluna (2) se refere ao cenário em que um possível planejador central impõe lucro nulo aos bancos, mantendo o custo por unidade de deslocamento do cenário base. Comparado com o cenário base, há um aumento de $1.2 \%$ no PIB e no bem-estar dos indivíduos. A demanda por crédito aumenta cerca de 16\%, consequência do crédito mais barato, o que por sua vez leva a um aumento na taxa de remuneração do ativo livre de risco para equilibrar os mercados. Ainda assim, a taxa de empréstimo cai de $10.5 \%$ para $9.8 \%$.

Há dois resultados curiosos, e à primeira vista contra intuitivos neste cenário. O primeiro é uma redução no percentual de empresários de $13.8 \%$ para 13.5\%. O segundo é a redução no percentual de micro firmas de $81.7 \%$ para $81.4 \%$. O mecanismo por trás dos dois resultados é o mesmo. Com o aumento na taxa de retorno do ativo livre de risco para equilibrar os mercados, os indivíduos que utilizam sua própria riqueza para financiar capital acabam tendo um custo maior, reduzindo o lucro. O resultado esperado é uma queda no número de indivíduos que se financiam. Apesar de a redução na taxa 
de empréstimo potencialmente incentivar mais indivíduos a emprestarem, para alguns tamanhos de firmas, este efeito acaba sendo ofuscado pela queda no número de indivíduos que usam a própria riqueza para se financiar.

A Fig. 11 traz o percentual de indivíduos donos de empresas, em função do número de funcionários de cada empresa e o tipo de financiamento utilizado. O primeiro gráfico se refere ao cenário base e o segundo ao cenário (2). Note que o percentual de indivíduos que se autofinanciam cai em todas os intervalos de tamanho de firmas, quando comparamos o cenário (2) com o cenário base. Por outro lado, o crédito mais barato faz o número de indivíduos que tomam empréstimos aumentar em praticamente todos os intervalos. Para firmas muito pequenas, com até 3 funcionários, o número de indivíduos que deixam de utilizar autofinanciamento é maior que o número de indivíduos que passam a tomar empréstimo. Nesta faixa, cerca de $0.54 \%$ dos indivíduos deixam de se autofinanciar, ao passo que $0.16 \%$ passam a tomar empréstimo. O efeito líquido é uma redução de 0.38 p.p. no número de indivíduos donos de firmas com até 3 funcionários. Note ainda que, para firmas com mais de 9 funcionários, o efeito líquido é ligeiramente positivo (0.04\%), mas não é capaz de compensar o efeito negativo para firmas com até 3 funcionários.

O efeito mencionado acima explica a redução tanto no número de empresários como na fração de micro firmas. A redução no número de empresários, combinada com o efeito ligeiramente positivo do mecanismo descrito acima para firmas maiores, contribui para aumentar ligeiramente a desigualdade de renda dos indivíduos, como observado pelo aumento do índice de Gini do cenário base para o 2.

As colunas (3) (4) e (5) apresentam os resultados dos cenários de redução no custo de deslocamento. A coluna (3) compreende o caso em que $\tau$ é reduzido pela metade. A coluna (4), o caso em que $\tau$ é reduzido para $1 / 4$ do valor do cenário base. A última coluna corresponde ao caso em que não há custo de deslocamento.

Ao reduzir o custo de deslocamento pela metade, há um aumento de $1 \%$ no PIB e 1.6\% no bem-estar. Há um aumento significativo tanto no acesso a crédito (15.9\%), quanto na demanda por crédito (10.3\%). Apesar da estratégia de equilíbrio de Nash dos bancos cair cerca de $36 \%$, o lucro dos bancos cai apenas $30 \%$, visto que o aumento na demanda por crédito mitiga uma parte do efeito da redução no spread. A queda do spread de equilíbrio é superior ao aumento da taxa de retorno do ativo necessário para equilibrar os mercados. Desta forma, a taxa de empréstimo cai para $10.4 \%$.

Reduzir $\tau$ para 0 elimina o poder de mercado dos bancos. O resultado é um equilíbrio de Nash e lucro dos bancos nulos. A eliminação do custo de deslocamento provoca um aumento de $1.8 \%$ no PIB e $3.9 \%$ no bem-estar. Comparando com o cenário da coluna (2), é possível separar os efeitos da existência do custo de deslocamento e do poder de mercado gerado aos bancos por ele. Do 1.8 p.p. de crescimento do produto no cenário (5), 1.2 p.p. pode ser atribuído ao poder de mercado dos bancos, e o restante à 
existência do custo de deslocamento. Por outro lado, para bem-estar, o efeito do custo de deslocamento é mais importante, respondendo por cerca de 2.7 p.p., enquanto o poder de mercado responde por 1.2 p.p..

Nota-se também um aumento na fração de empresários e uma mudança na distribuição de tamanho de firmas no cenário (5), com aumento da participação de firmas micro, e redução da fração de pequenas empresas. A comparação do cenário base com o cenário (5) da Fig. 11 permite entender o que gera tais efeitos. Há uma redução de 2.4 p.p. no percentual de indivíduos que se autofinanciam, acompanhado de um aumento de 3.2 p.p. no percentual de indivíduos que tomam empréstimos. O resultado líquido é o aumento observado de 0.8 p.p. no percentual de empresários.

Comparando a distribuição de tamanho de firmas, há um aumento de 0.9 p.p. no percentual de indivíduos donos de micro firmas, o que corresponde a um aumento de $8.2 \%$ no número de micro firmas. Por outro lado, há uma ligeira redução no percentual de indivíduos donos de firmas com mais de 9 funcionários (0.1 p.p.). Logo, a redução no percentual de firmas pequenas é majoritariamente causada por um efeito diluição do número destas firmas, dado o aumento do número de empresários. De fato, do 1.7 p.p. de queda na fração de empresas pequenas, aproximadamente 1 p.p. pode ser atribuído a este efeito diluição.

A redução do custo por unidade de deslocamento causa um aumento na TFP nos três cenários considerados. Comparado ao cenário base, a TFP aumenta em 1\%, 1.7\% e $2.2 \%$ respectivamente nos cenários $(3)$, (4) e (5). Há dois mecanismos que explicam o aumento da produtividade. A queda do custo por unidade de deslocamento causa uma maior inclusão financeira, tanto pela queda do custo, como pela diminuição na taxa de empréstimo. Isto permite que indivíduos com elevada produtividade, antes sem acesso a crédito, se tornem empresários. Além disso, o aumento da taxa de retorno do ativo livre de risco faz com que parte dos indivíduos que financiavam sua necessidade de capital com riqueza própria deixem de ser empresários. Tais indivíduos possuíam um baixo nível de produtividade.

Por fim, há uma redução no índice de Gini nos cenários (3), (4) e (5). A redução na desigualdade nestes três cenários é consequência de dois efeitos. O primeiro é relacionado ao crédito mais barato, aumentando tanto o número de empresários como o salário pago aos trabalhadores, devido ao aumento na demanda por trabalho. O segundo efeito é consequência da redução no custo por unidade de deslocamento, o que torna os indivíduos menos "diferentes", já que a posição do indivíduo passa a influenciar menos nas suas características.

É importante ressaltar que o efeito de redução de spread causado pela redução do custo por unidade de deslocamento nos cenários contrafactuais acima estão subestimados. A redução da margem financeira dos bancos, causada pela redução na estratégia de equilíbrio 
de Nash dos bancos, causaria, em teoria, uma redução nos impostos pagos por eles. Como mantivemos $\epsilon$ constante em todos os cenários, não capturamos o efeito de redução no spread devido à redução na quantidade de impostos pagos. Com um efeito subestimado de impacto no spread, é razoável supor que os impactos em bem-estar e produto também estejam.

Figura 11 - Distribuição de indivíduos por tamanho de empresa e forma de financiamento

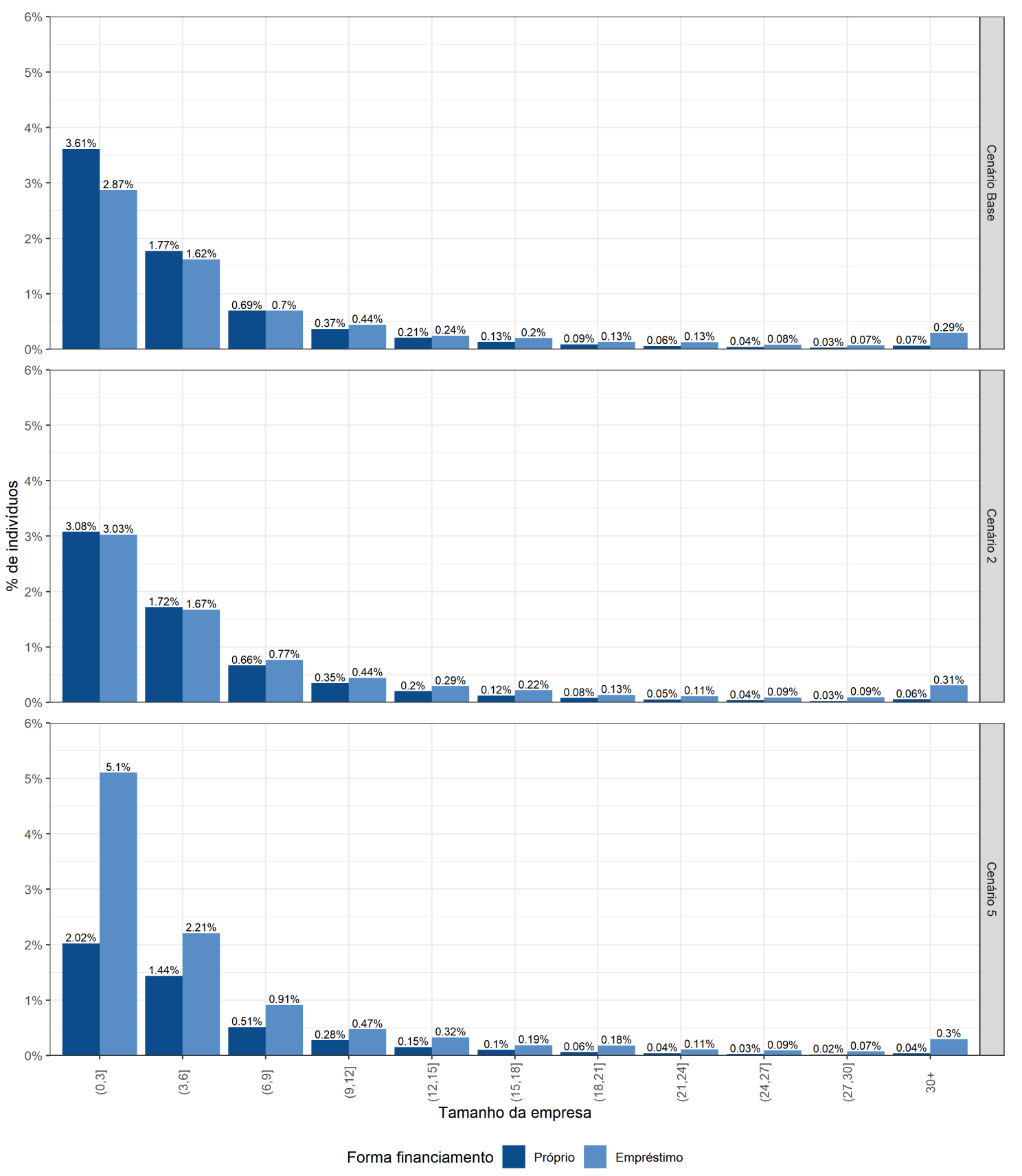

Fonte - Elaboração própria. 


\section{Conclusão}

Neste trabalho, procuramos entender qual o efeito da competição bancária nos spreads praticados no Brasil e algumas de suas consequências. Combinando o modelo proposto em Aiyagari (1994) com uma competição à la Hotelling dos bancos, avaliamos o papel da distância entre os indivíduos e as instituições financeiras tanto no spread cobrado por elas quanto em diversas características de cada indivíduo. Interpretamos esta distância não apenas como uma distância física, mas que incorpora também efeitos do relacionamento entre tomadores de crédito e bancos. Neste contexto, o custo de deslocamento pode ser entendido como despesas relacionadas ao fornecimento de informações financeiras requisitadas pelos bancos para conceder empréstimos.

Para quantificar tais efeitos, utilizamos um modelo com agentes heterogêneos em três dimensões, em tempo contínuo, cuja solução é uma adaptação da proposta inicialmente em Achdou et al. (2021). O modelo é calibrado de modo a replicar alguns momentos dos dados brasileiros, como distribuição de tamanho de firmas, acesso a crédito, taxa de retorno do ativo livre de risco e volume de crédito emprestado em relação ao PIB.

Iniciativas como open banking que facilitem o acesso a informações financeiras dos indivíduos, diminuindo o papel do relacionamento entre tomadores e bancos no processo de concessão de empréstimo, contribuem para reduzir este custo por unidade de deslocamento. Nossas análises quantitativas indicam que há impactos positivos caso este custo fosse eliminado. Haveria um crescimento de $1.8 \%$ no produto e $3.9 \%$ no bem-estar. Do 1.8 p.p. (3.9 p.p.) de crescimento no produto (bem-estar), 1.2 p.p. (1.2 p.p.) pode ser atribuído ao efeito do poder de mercado gerado pelo custo de deslocamento aos bancos, sendo o restante atribuído ao próprio custo.

Nossos resultados indicam ainda que a eliminação deste custo aumentaria em aproximadamente $8 \%$ o número de micro firmas. De fato, as microempresas são as mais impactadas pela existência deste custo e as que potencialmente seriam mais beneficiadas com a eliminação do mesmo. Tal resultado é condizente com a literatura já existente sobre relationship banking e o papel da distância física no mercado de crédito.

Este é um trabalho pioneiro que utiliza modelos com agentes heterogêneos para entender o papel da competição bancária no mercado de crédito brasileiro. Acreditamos que o ferramental desenvolvido aqui pode ser explorado para entender outras questões. A quebra da simetria na disposição dos bancos, ou uma distribuição não uniforme de indivíduos ao longo da circunferência, por exemplo, pode ser utilizada para entender questões envolvendo competição em ambientes com diferentes graus de concentração bancária. 


\section{Referências}

ACHDOU, Yves et al. Income and Wealth Distribution in Macroeconomics: A Continuous-

Time Approach. Review of Economic Studies, forthcoming, 2021. Citado nas páginas ix, xi, 16, 29, 41, 45.

AGARWAL, Sumit. Distance and Private Information in Lending. Review of Financial Studies, Society for Financial Studies, v. 23, n. 7, p. 2757-2788, 2010. Citado na página 3.

AIYAGaRI, S. R. Uninsured Idiosyncratic Risk and Aggregate Saving. The Quarterly Journal of Economics, v. 109, n. 3, p. 659-684, 1 ago. 1994. Citado nas páginas ix, xi, $2,12,29$.

Banco Central do Brasil. Relatório de Economia Bancária. 2019. Citado nas páginas $6,9,18,20$.

BAnerJee, Abhijit V.; Duflo, Esther. Giving Credit Where It Is Due. Journal of Economic Perspectives, v. 24, n. 3, p. 61-80, set. 2010. Citado na página 13.

Boone, Jan. A New Way to Measure Competition. The Economic Journal, [Royal Economic Society, Wiley], v. 118, n. 531, p. 1245-1261, 2008. Citado na página 4.

Bоoт, Arnoud W. A. Relationship Banking: What Do We Know? Journal of Financial Intermediation, Elsevier, v. 9, n. 1, p. 7-25, 2000. Citado na página 2.

BUERA, Francisco J.; SHIN, Yongseok. Financial Frictions and the Persistence of History: A

Quantitative Exploration. Journal of Political Economy, The University of Chicago Press, v. 121, n. 2, p. 221-272, 2013. Citado na página 13.

CANDler, Graham V. Finite-Difference Methods for Continuous-Time Dynamic Programming. In: marimon, Ramon; scotT, Andrew (Ed.). Computational Methods for the Study of Dynamic Economies. Oxford University Press, 18 out. 2001. P. 172-194. Citado na página 43.

Cavalcanti, Tiago et al. Dispersion in Financing Costs and Development. Cambridge, MA, abr. 2021. w28635. Citado nas páginas 4, 8, 18-20.

Coleman, Thomas F.; LI, Yuying. An Interior Trust Region Approach for Nonlinear Minimization Subject to Bounds. SIAM Journal on Optimization, Society for Industrial \& Applied Mathematics (SIAM), 1 mai. 1996. Citado na página 49.

DEGRYSe, Hans; Ongena, Steven. Distance, Lending Relationships, and Competition. The Journal of Finance, [American Finance Association, Wiley], v. 60, n. 1, p. 231-266, 2005. Citado na página 3. 
DIXIT, A. Art of Smooth Pasting: 55. $1^{\mathrm{a}}$ edição. Chur, Switzerland ; Langhorne, Pa., USA: Routledge, 11 mai. 1993. Citado na página 45.

Drexler, Alejandro; SCHOAR, Antoinette. Do Relationships Matter? Evidence from Loan Officer Turnover. Management Science, INFORMS, v. 60, n. 11, p. 2722-2736, 2014. Citado na página 2.

Evans, David S.; Jovanovic, Boyan. An Estimated Model of Entrepreneurial Choice under Liquidity Constraints. Journal of Political Economy, University of Chicago Press, v. 97, n. 4, p. 808-827, 1989. Citado na página 12.

Feenstra, Robert C.; InklaAr, Robert; timmer, Marcel P. The Next Generation of the Penn World Table. The American Economic Review, American Economic Association, v. 105, n. 10, p. 3150-3182, 2015. Citado na página 18.

Gollin, Douglas. Getting Income Shares Right. Journal of Political Economy, The

University of Chicago Press, v. 110, n. 2, p. 458-474, 2002. Citado nas páginas 18, 20. Hotelling, Harold. Stability in Competition. The Economic Journal, [Royal Economic Society, Wiley], v. 39, n. 153, p. 41-57, 1929. Citado nas páginas 2, 10.

JoAquim, Gustavo; Doornik, Bernardus Van; ORnelas, José Renato. Bank Competition, Cost of Credit and Economic Activity: Evidence from Brazil. Out. 2019. (Working Papers Series, 508). Citado nas páginas 3, 6.

JUdD, Kenneth L. Numerical Methods in Economics. Cambridge, Mass: The MIT Press, 27 out. 1998. 656 p. Citado na página 49.

LucAs, Robert E. On the Size Distribution of Business Firms. The Bell Journal of Economics, [RAND Corporation, Wiley], v. 9, n. 2, p. 508-523, 1978. Citado nas páginas 10, 11.

MADEIRA, Gabriel A. Effects of a Financial Crisis on Occupational Choice: An Empirical Evaluation. Mimeo, 2008. Citado na página 21.

MADEIRA, Gabriel A. et al. Impactos Do Direcionamento de Crédito Sobre a

Economia Brasileira: Uma Abordagem de Equilíbrio Geral. Dez. 2018. (Working Papers Series, 490). Citado nas páginas 4, 13, 18-20.

NAKAne, Márcio Issao. A Test of Competition in Brazilian Banking. Estudos Econômicos

(São Paulo), v. 32, n. 2, p. 203-224, 21 jun. 2002. Citado na página 4.

nguyen, Hoai-Luu Q. Are Credit Markets Still Local? Evidence from Bank Branch

Closings. American Economic Journal: Applied Economics, v. 11, n. 1, p. 1-32, jan. 2019. Citado na página 3.

OECD. Financing SMEs and Entrepreneurs 2020. 2020. 
Petersen, Mitchell A.; RAJAn, Raghuram G. Does Distance Still Matter? The Information Revolution in Small Business Lending. The Journal of Finance, v. 57, n. 6, p. 25332570, 2002. Citado nas páginas 2, 3.

Sanches, Fábio A. Miessi; Rocha, Bruno de Paula; silva, José Carlos Domingos da.

Estimating a Theoretical Model of State Banking Competition Using a Dynamic Panel: The Brazilian Case. Revista Brasileira de Economia, Fundação Getúlio Vargas, v. 63, p. 23-34, mar. 2009. Citado na página 4.

SAntos, Fernando Kuwer dos. Earmarked Credit and Misallocation: Evidence

from Brazil. 21 jul. 2016. Dissertação de Mestrado - Universidade de São Paulo. Citado na página 21.

SOUZA-SOBRinho, Nelson F. Macroeconomics of Bank Interest Spreads: Evidence from

Brazil. Annals of Finance, v. 6, n. 1, p. 1, 4 set. 2009. Citado na página 5.

Stokey, Nancy L. The Economics of Inaction: Stochastic Control Models with

Fixed Costs. Princeton: Princeton University Press, 2009. 308 p. Citado na página 41.

TABAK, Benjamin M.; FAZIo, Dimas M.; CAJueiro, Daniel O. The Relationship between

Banking Market Competition and Risk-Taking: Do Size and Capitalization Matter?

Journal of Banking \& Finance, v. 36, n. 12, p. 3366-3381, 1 dez. 2012. Citado na página 4.

THE WORLD BANK. Enterprise Surveys - The World Bank. Disponível em: <https:

//www. enterprisesurveys.org >. Acesso em: 10 fev. 2021.

THE WORLD BANK. Global Financial Development Report 2019/2020: Bank

Regulation and Supervision a Decade after the Global Financial Crisis.

2019. Disponível em: <https://www.worldbank.org/en/publication/gfdr/data/ global-financial-development-database>. Acesso em: 25 jan. 2021.

TOWnsend, Robert M; ZHORIn, Victor V. Spatial Competition among Financial Service Providers and Optimal Contract Design. Unpublished, 2015. Citado na página 50. 
Apêndices 


\section{APÊNDICE A - Derivações Teóricas}

\section{A.1 Hamilton-Jacobi-Bellman}

A função valor do problema do indivíduo é dada por:

$$
v\left(a_{t}, z_{t}, \theta_{t}\right)=\operatorname{máx}_{\left\{c_{t}\right\}_{t \in[0, \infty)}} \mathbb{E}_{0}\left[\int_{0}^{\infty} e^{-\rho t} u\left(c_{t}\right) \mathrm{d} t\right]
$$

sujeito as restrições:

$$
\begin{aligned}
\dot{a}_{t} & =r_{t} a_{t}+y\left(a_{t}, z_{t}, \theta_{t}\right)-c_{t} \\
\mathrm{~d} z_{t} & =\mu\left(z_{t}\right) \mathrm{d} t+\sigma\left(z_{t}\right) \mathrm{d} W_{t}
\end{aligned}
$$

em que $\mu\left(z_{t}\right)$ e $\sigma\left(z_{t}\right)$ são dados por:

$$
\begin{aligned}
& \mu\left(z_{t}\right)=\left(-\varphi \ln z_{t}+\frac{\zeta^{2}}{2}\right) z_{t} \\
& \sigma\left(z_{t}\right)=\zeta z_{t}
\end{aligned}
$$

e $W_{t}$ é um processo de Wiener, isto é, $\mathrm{d} W_{t} \sim \mathcal{N}(0, \mathrm{~d} t)$.

Considerando um pequeno intervalo de tempo $\Delta$ com indivíduos descontando o futuro a uma taxa $\beta(\Delta)=e^{-\rho \Delta}$, a equação de Bellman para o análogo em tempo discreto deste problema é:

$$
v\left(a_{t}, z_{t}, \theta_{t}\right)=\operatorname{máx}_{c_{t}}\left\{u\left(c_{t}\right) \Delta+\beta(\Delta) \mathbb{E}\left[v\left(a_{t+\Delta}, z_{t+\Delta}, \theta_{t+\Delta}\right)\right]\right\}
$$

Para um intervalo de tempo pequeno, podemos aproximar a taxa de desconto por uma expansão de Taylor de primeira ordem: $\beta(\Delta) \approx 1-\rho \Delta$. Substituindo, vem:

$$
v\left(a_{t}, z_{t}, \theta_{t}\right)=\operatorname{máx}_{c_{t}}\left\{u\left(c_{t}\right) \Delta+(1-\rho \Delta) \mathbb{E}\left[v\left(a_{t+\Delta}, z_{t+\Delta}, \theta_{t+\Delta}\right)\right]\right\}
$$

Subtraindo $(1-\rho \Delta) v\left(a_{t}, z_{t}, \theta_{t}\right)$ em ambos os lados:

$$
\rho \Delta v\left(a_{t}, z_{t}, \theta_{t}\right)=\operatorname{máx}_{c_{t}}\left\{u\left(c_{t}\right) \Delta+(1-\rho \Delta) \mathbb{E}\left[v\left(a_{t+\Delta}, z_{t+\Delta}, \theta_{t+\Delta}\right)-v\left(a_{t}, z_{t}, \theta_{t}\right)\right]\right\}
$$

Dividindo ambos os lados por $\Delta$ e fazendo $\Delta \rightarrow 0$ :

$$
\rho v\left(a_{t}, z_{t}, \theta_{t}\right)=\operatorname{máx}_{c_{t}}\left\{u\left(c_{t}\right)+\frac{\mathbb{E}\left[\mathrm{d} v\left(a_{t}, z_{t}, \theta_{t}\right)\right]}{\mathrm{d} t}\right\}
$$

Para determinar o termo $\mathbb{E}\left[v\left(a_{t}, z_{t}, \theta_{t}\right)\right] / \mathrm{d} t$, expandimos em Taylor $v(a, z, \theta)$ :

$$
\mathrm{d} v=\frac{\partial v}{\partial a} \mathrm{~d} a+\frac{\partial v}{\partial z} \mathrm{~d} z+\frac{\partial v}{\partial \theta} \mathrm{d} \theta+\frac{1}{2} \frac{\partial^{2} v}{\partial z^{2}} \mathrm{~d} z^{2} \ldots
$$


Substituindo $\mathrm{d} z=\mu\left(z_{t}\right) \mathrm{d} t+\sigma\left(z_{t}\right) \mathrm{d} W_{t}$, vem:

$$
\mathrm{d} v=\frac{\partial v}{\partial a} \mathrm{~d} a+\frac{\partial v}{\partial z} \cdot\left(\mu\left(z_{t}\right) \mathrm{d} t+\sigma\left(z_{t}\right) \mathrm{d} W_{t}\right)+\frac{\partial v}{\partial \theta} \mathrm{d} \theta+\frac{1}{2} \frac{\partial^{2} v}{\partial z^{2}} \cdot\left(\mu\left(z_{t}\right) \mathrm{d} t+\sigma\left(z_{t}\right) \mathrm{d} W_{t}\right)^{2} \ldots
$$

No limite $\mathrm{d} t \rightarrow 0$, os termos $\mathrm{d} t^{2}, \mathrm{~d} t \mathrm{~d} W_{t}$ e demais termos de ordem superior são desprezíveis em relação a $\mathrm{d} W_{t}^{2}, \operatorname{logo}$ :

$$
\mathrm{d} v=\frac{\partial v}{\partial a} \mathrm{~d} a+\frac{\partial v}{\partial z} \cdot\left(\mu\left(z_{t}\right) \mathrm{d} t+\sigma\left(z_{t}\right) \mathrm{d} W_{t}\right)+\frac{\partial v}{\partial \theta} \mathrm{d} \theta+\frac{1}{2} \frac{\partial^{2} v}{\partial z^{2}} \cdot \sigma^{2}\left(z_{t}\right) \mathrm{d} W_{t}^{2}
$$

Tomando a esperança em ambos os lados e usando $\mathbb{E}\left[\mathrm{d} W_{t}\right]=0$ e $\mathbb{E}\left[\mathrm{d} W_{t}^{2}\right]=\mathrm{d} t$, vem:

$$
\begin{aligned}
\mathbb{E}[\mathrm{d} v] & =\frac{\partial v}{\partial a} \mathrm{~d} a+\frac{\partial v}{\partial z} \cdot \mu\left(z_{t}\right) \mathrm{d} t+\frac{\partial v}{\partial \theta} \mathrm{d} \theta+\frac{1}{2} \frac{\partial^{2} v}{\partial z^{2}} \cdot \sigma^{2}\left(z_{t}\right) \mathrm{d} t \Rightarrow \\
\frac{\mathbb{E}[\mathrm{d} v]}{\mathrm{d} t} & =\frac{\partial v}{\partial a} \frac{\mathrm{d} a}{\mathrm{~d} t}+\frac{\partial v}{\partial z} \cdot \mu\left(z_{t}\right)+\frac{\partial v}{\partial \theta} \frac{\mathrm{d} \theta}{\mathrm{d} t}+\frac{1}{2} \frac{\partial^{2} v}{\partial z^{2}} \cdot \sigma^{2}\left(z_{t}\right)
\end{aligned}
$$

Como a posição $\theta$ é fixa no tempo, $\mathrm{d} \theta / \mathrm{d} t=0$, logo:

$$
\frac{\mathbb{E}[\mathrm{d} v]}{\mathrm{d} t}=\frac{\partial v}{\partial a} \cdot \underbrace{\left(r_{t} a_{t}+y\left(a_{t}, z_{t}, \theta_{t}\right)-c_{t}\right)}_{\mathrm{d} a / \mathrm{d} t}+\frac{\partial v}{\partial z} \cdot \mu\left(z_{t}\right)+\frac{1}{2} \frac{\partial^{2} v}{\partial z^{2}} \cdot \sigma^{2}\left(z_{t}\right)
$$

Substituindo $\mathbb{E}[\mathrm{d} v] / \mathrm{d} t$ na Eq. (A.1) obtemos a Hamilton-Jacobi-Bellman:

$$
\begin{array}{r}
\rho v\left(a_{t}, z_{t}, \theta_{t}\right)=\operatorname{máx}_{c_{t}}\left\{u\left(c_{t}\right)+\partial_{a} v\left(a_{t}, z_{t}, \theta_{t}\right)\left[r_{t} a_{t}+y\left(a_{t}, z_{t}, \theta_{t}\right)-\right.\right. \\
\left.-c_{t}\right]+\partial_{z} v\left(a_{t}, z_{t}, \theta_{t}\right) \mu\left(z_{t}\right) \\
\left.+\frac{1}{2} \partial_{z z} v\left(a_{t}, z_{t}, \theta_{t}\right) \sigma^{2}\left(z_{t}\right)\right\}
\end{array}
$$

\section{A.2 Problema da Firma}

Começaremos apresentando a solução do problema da firma quando esta se depara com a decisão de emprestar de algum banco $j \in \mathcal{J}$. Não nos preocuparemos com os possíveis casos em que a solução do problema de maximização do lucro da firma levar a um lucro negativo pois, neste caso, o indivíduo não decidirá empreender, aceitando trabalhar recebendo o salário $w$. O problema da firma neste caso é dado por:

$$
\begin{array}{ll}
\pi_{e, j}=\operatorname{máx}_{\{k, \ell\}} & z\left(k^{\alpha} \ell^{1-\alpha}\right)^{\phi}-w \ell-\left(r_{e, j}+\delta\right)(k-a)-a(r+\delta)-\mathrm{c}\left(\theta^{i}, \beta_{j}\right) \\
\text { sujeito a: } & a \leq k \leq \lambda a
\end{array}
$$

O Lagrangeano associado a este problema é:

$$
\mathscr{L}=z\left(k^{\alpha} \ell^{1-\alpha}\right)^{\phi}-w \ell-\left(r_{e, j}+\delta\right)(k-a)-a(r+\delta)-c\left(\theta^{i}, \beta_{j}\right)+\mu_{1}(k-a)+\mu_{2}(\lambda a-k)
$$

em que $\mu_{1}$ e $\mu_{2}$ são os multiplicadores de Kuhn-Tucker. As condições de Kuhn-Tucker são dadas por: 


$$
\begin{aligned}
\frac{\partial \mathscr{L}}{\partial k_{e, j}} & =0 \Rightarrow z \alpha \phi k_{e, j}^{\alpha \phi-1} \ell_{e, j}^{(1-\alpha) \phi}-\left(r_{e, j}+\delta\right)+\mu_{1}-\mu_{2}=0 \\
\frac{\partial \mathscr{L}}{\partial \ell_{e, j}} & =0 \Rightarrow z(1-\alpha) \phi k_{e, j}^{\alpha \phi} \ell_{e, j}^{(1-\alpha) \phi-1}-w=0 \\
\mu_{1}\left(k_{e, j}-a\right) & =0 \\
\mu_{2}\left(\lambda a-k_{e, j}\right) & =0
\end{aligned}
$$

Temos três casos a considerar:

Caso 1: $a<k_{e, j}<\lambda a$

Neste caso, nenhuma das restrições está ativa, então $\mu_{1}=\mu_{2}=0$. Pode-se mostrar que as demandas por capital e por trabalho e o lucro da firma serão dadas por:

$$
\begin{aligned}
k_{e, j} & =\left[z \phi\left(\frac{\alpha}{r_{e, j}+\delta}\right)^{1-(1-\alpha) \phi}\left(\frac{1-\alpha}{w}\right)^{(1-\alpha) \phi}\right]^{\frac{1}{1-\phi}} \\
\ell_{e, j} & =\frac{k_{e, j}\left(r_{e, j}+\delta\right)(1-\alpha)}{\alpha w} \\
\pi_{e, j} & =(1-\phi)\left[z \phi^{\phi}\left(\frac{\alpha}{r_{e, j}+\delta}\right)^{\alpha \phi}\left(\frac{1-\alpha}{w}\right)^{(1-\alpha) \phi}\right]^{\frac{1}{1-\phi}}+a\left(r_{e, j}-r\right)-c\left(\theta^{i}, \beta_{j}\right)
\end{aligned}
$$

Para que esta solução seja válida, devemos ter $a<k_{e, j}<\lambda a$. Rearranjando os termos na Eq. (A.6), esta condição se torna:

$$
\frac{a^{1-\phi}}{\phi\left(\frac{\alpha}{r_{e, j}+\delta}\right)^{1-(1-\alpha) \phi}\left(\frac{1-\alpha}{w}\right)^{1-\alpha \phi}}<z<\frac{\lambda^{1-\phi} a^{1-\phi}}{\phi\left(\frac{\alpha}{r_{e, j}+\delta}\right)^{1-(1-\alpha) \phi}\left(\frac{1-\alpha}{w}\right)^{1-\alpha \phi}}
$$

Caso 2: $\mathrm{O}$ indivíduo prefere não tomar empréstimo, isto é $k_{e, j}=a$ :

Neste caso temos: $\mu_{2}=0$ e $\mu_{1} \geq 0$. Logo:

$$
\begin{aligned}
& k_{e, j}=a \\
& \ell_{e, j}=\left[\frac{z(1-\alpha) \phi a^{\alpha \phi}}{w}\right]^{\frac{1}{1-(1-\alpha) \phi}} \\
& \pi_{e, j}=[1-(1-\alpha) \phi]\left[z a^{\alpha \phi}\left(\frac{(1-\alpha) \phi}{w}\right)^{(1-\alpha) \phi}\right]^{\frac{1}{1-(1-\alpha) \phi}}-a(r+\delta)
\end{aligned}
$$

Para que $\mu_{1} \geq 0$, devemos ter:

$$
\left(r_{e, j}+\delta\right)-z \alpha \phi k_{e, j}^{\alpha \phi-1} \ell_{e, j}^{(1-\alpha) \phi} \geq 0
$$

Substituindo a Eq. (A.7) e rearranjando os termos vem:

$$
z \leq \frac{a^{1-\phi}}{\phi\left(\frac{\alpha}{r_{e, j}+\delta}\right)^{1-(1-\alpha) \phi}\left(\frac{1-\alpha}{w}\right)^{(1-\alpha) \phi}}
$$


Caso 3: A restrição de compatibilidade de incentivos está ativa, isto é, $k_{e, j}=\lambda a$.

Neste caso, $\mu_{1}=0$ e $\mu_{2} \geq 0$. Logo:

$$
\begin{gathered}
k_{e, j}=\lambda a \\
\ell_{e, j}=\left[\frac{z(1-\alpha) \phi(\lambda a)^{\alpha \phi}}{w}\right]^{\frac{1}{1-(1-\alpha) \phi}} \\
\pi_{e, j}=[1-(1-\alpha) \phi]\left[z(\lambda a)^{\alpha \phi}\left(\frac{(1-\alpha) \phi}{w}\right)^{(1-\alpha) \phi}\right]^{\frac{1}{1-(1-\alpha) \phi}}-a\left[(\lambda-1) r_{e, j}+\lambda \delta+r\right]- \\
c\left(\theta^{i}, \beta_{j}\right)
\end{gathered}
$$

Para que $\mu_{2} \geq 0$, devemos ter:

$$
z \alpha \phi k_{e, j}^{\alpha \phi-1} \ell_{e, j}^{(1-\alpha) \phi}-\left(r_{e, j}+\delta\right) \geq 0
$$

Substituindo a Eq. (A.8) e rearranjando os termos:

$$
z \geq \frac{\lambda^{1-\phi} a^{1-\phi}}{\phi\left(\frac{\alpha}{r_{e, j}+\delta}\right)^{1-(1-\alpha) \phi}\left(\frac{1-\alpha}{w}\right)^{(1-\alpha) \phi}}
$$

Por fim, resta considerar o problema da firma quando o indivíduo se depara com a decisão de se financiar com a sua própria riqueza. O problema da firma neste caso é dado por:

$$
\begin{array}{ll}
\pi_{a}=\operatorname{máx}_{\{k, \ell\}} & z\left(k^{\alpha} \ell^{1-\alpha}\right)^{\phi}-w \ell-(r+\delta) k \\
\text { sujeito a: } & k \leq a
\end{array}
$$

Este problema é análogo ao problema da firma quando decide tomar empréstimo que tratamos anteriormente. Chamando de $k_{a}$ e $\ell_{a}$ a solução do problema acima, temos dois casos a considerar:

Caso 5: $k_{a}<a$

As demandas por empréstimo e por trabalho e o lucro da firma são dados por:

$$
\begin{aligned}
k_{a} & =\left[z \phi\left(\frac{\alpha}{r+\delta}\right)^{1-(1-\alpha) \phi}\left(\frac{1-\alpha}{w}\right)^{(1-\alpha) \phi}\right]^{\frac{1}{1-\phi}} \\
\ell_{a} & =\frac{k_{a}(r+\delta)(1-\alpha)}{\alpha w} \\
\pi_{a} & =(1-\phi)\left[z \phi^{\phi}\left(\frac{\alpha}{r+\delta}\right)^{\alpha \phi}\left(\frac{1-\alpha}{w}\right)^{(1-\alpha) \phi}\right]^{\frac{1}{1-\phi}}
\end{aligned}
$$

Esta solução será válida se:

$$
z<\frac{a^{1-\phi}}{\phi\left(\frac{\alpha}{r+\delta}\right)^{1-(1-\alpha) \phi}\left(\frac{1-\alpha}{w}\right)^{1-\alpha \phi}}
$$


Caso 6: $k_{a}=a$

As demandas por empréstimo e por trabalho e o lucro da firma são dados por:

$$
\begin{aligned}
k_{a} & =a \\
\ell_{a} & =\left[\frac{z(1-\alpha) \phi a^{\alpha \phi}}{w}\right]^{\frac{1}{1-(1-\alpha) \phi}} \\
\pi_{a} & =[1-(1-\alpha) \phi]\left[z a^{\alpha \phi}\left(\frac{(1-\alpha) \phi}{w}\right)^{(1-\alpha) \phi}\right]^{\frac{1}{1-(1-\alpha) \phi}}-a(r+\delta)
\end{aligned}
$$

Esta solução será válida se:

$$
z \geq \frac{a^{1-\phi}}{\phi\left(\frac{\alpha}{r+\delta}\right)^{1-(1-\alpha) \phi}\left(\frac{1-\alpha}{w}\right)^{1-\alpha \phi}}
$$

As cinco condições acima determinam quatro regiões distintas no plano $z \times a$. A Fig. 12 ilustra a decisão de financiamento da firma para valores hipotéticos dos parâmetros. A região "Não Empresta Restrição Inativa" corresponde aos indivíduos para os quais a sua riqueza é maior que a sua necessidade de capital. A região "Não empresta Restrição ativa" corresponde aos indivíduos que usam toda a sua riqueza para se financiar, mas não emprestam. A região "Empresta Restrição Inativa" corresponde aos indivíduos que tomam empréstimo, mas não são limitados pela restrição de compatibilidade de incentivos. Por fim, a região "Empresta Restrição Ativa" corresponde aos indivíduos que emprestam e ficam limitados pela restrição de compatibilidade de incentivos.

Figura 12 - Forma de financiamento de capital

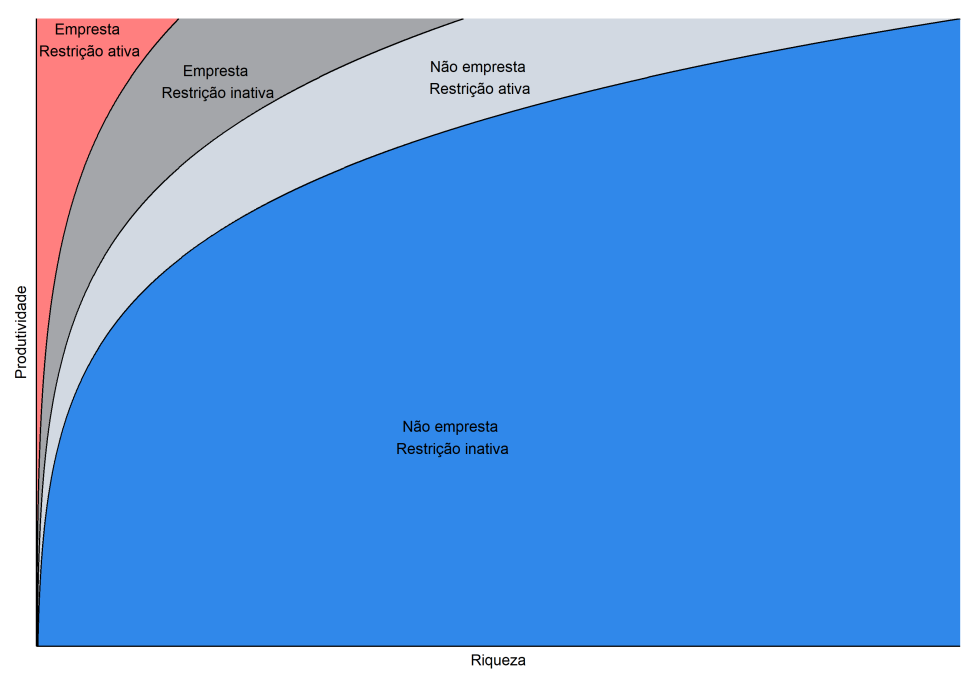

Fonte - Elaboração própria 


\section{A.3 Escolha ocupacional}

A partir da solução do problema da firma, apresentado na seção anterior, podemos derivar a solução para o problema da escolha ocupacional do indivíduo, comparando o lucro da firma em cada um dos casos da seção anterior com a renda do trabalho que o indivíduo receberia caso decidisse trabalhar.

Caso 1: Indivíduo decide se financiar e sua riqueza é mais que suficiente para cobrir a necessidade de capital.

Neste caso, o indivíduo decidirá trabalhar se:

$$
\begin{aligned}
\pi_{a} & =(1-\phi)\left[z \phi^{\phi}\left(\frac{\alpha}{r+\delta}\right)^{\alpha \phi}\left(\frac{1-\alpha}{w}\right)^{(1-\alpha) \phi}\right]^{\frac{1}{1-\phi}} \leq w \Rightarrow \\
z & \leq \frac{w^{1-\phi}}{(1-\phi)^{1-\phi}\left[\phi^{\phi}\left(\frac{\alpha}{r+\delta}\right)^{\alpha \phi}\left(\frac{1-\alpha}{w}\right)^{(1-\alpha) \phi}\right]}
\end{aligned}
$$

A condição acima está associada a um limiar em z, representado por uma reta, dos indivíduos que estão indiferentes entre empreender e trabalhar. Tal reta é representada pela reta 1 na Fig. 13.

Caso 2: Indivíduo decide se financiar e utiliza toda riqueza sem tomar empréstimo.

Neste caso, o indivíduo decidirá trabalhar se:

$$
\begin{aligned}
\pi_{a} & =[1-(1-\alpha) \phi]\left[z a^{\alpha \phi}\left(\frac{(1-\alpha) \phi}{w}\right)^{(1-\alpha) \phi}\right]^{\frac{1}{1-(1-\alpha) \phi}}-a(r+\delta) \leq w \Rightarrow \\
z & \leq \frac{1}{a^{\alpha \phi}\left(\frac{(1-\alpha) \phi}{w}\right)^{(1-\alpha) \phi}} \cdot\left[\frac{w+a(r+\delta)}{1-(1-\alpha) \phi}\right]^{1-(1-\alpha) \phi}
\end{aligned}
$$

A condição acima determina uma curva no plano $z \times a$ dos indivíduos que ficam indiferentes entre trabalhar e empreender. Tal curva é ilustrada pela curva 2 na Fig. 13.

Caso 3: Indivíduo decide tomar empréstimo, mas não é afetado pela restrição de compatibilidade de incentivos.

Neste caso, o indivíduo decidirá trabalhar se:

$$
\begin{aligned}
\pi_{e, j} & =(1-\phi)\left[z \phi^{\phi}\left(\frac{\alpha}{r_{e, j}+\delta}\right)^{\alpha \phi}\left(\frac{1-\alpha}{w}\right)^{(1-\alpha) \phi}\right]^{\frac{1}{1-\phi}}+a\left(r_{e, j}-r\right)-c\left(\theta^{i}, \beta_{j}\right) \leq w \Rightarrow \\
a & \leq \frac{w+c\left(\theta^{i}, \beta_{j}\right)}{r_{e, j}-r}-\frac{(1-\phi)}{r_{e, j}-r}\left[z \phi^{\phi}\left(\frac{\alpha}{r_{e, j}+\delta}\right)^{\alpha \phi}\left(\frac{1-\alpha}{w}\right)^{(1-\alpha) \phi}\right]^{\frac{1}{1-\phi}}
\end{aligned}
$$

A condição acima associa, para cada valor de produtividade, um limiar na riqueza para o qual o indivíduo fica indiferente entre trabalhar e empreender. Este limiar está representado pela curva 3 na Fig. 13. 
Caso 4: Indivíduo decide tomar empréstimo e é limitado pela restrição de compatibilidade de incentivos.

Neste caso, o indivíduo decidirá trabalhar se:

$$
\begin{aligned}
\pi_{e, j} & \leq w \Rightarrow \\
z & \leq \frac{1}{(\lambda a)^{\alpha \phi}\left(\frac{(1-\alpha) \phi}{w}\right)^{(1-\alpha) \phi}}\left[\frac{w+a\left[(\lambda-1) r_{e, j}+\lambda \delta+r\right]+c\left(\theta^{i}, \beta_{j}\right)}{1-(1-\alpha) \phi}\right]^{1-(1-\alpha) \phi}
\end{aligned}
$$

A condição acima determina, uma curva no plano $z \times a$ dos indivíduos que ficam indiferentes entre trabalhar e empreender. Tal curva é ilustrada pela curva 4 da Fig. 13.

Combinando as 4 curvas acima com as regiões previamente determinadas na solução do problema da firma, obtemos a escolha ocupacional do indivíduo para cada par possível de riqueza e produtividade. A Fig. 13 ilustra a decisão do indivíduo para valores hipotéticos dos parâmetros do modelo.

Figura 13 - Escolha ocupacional

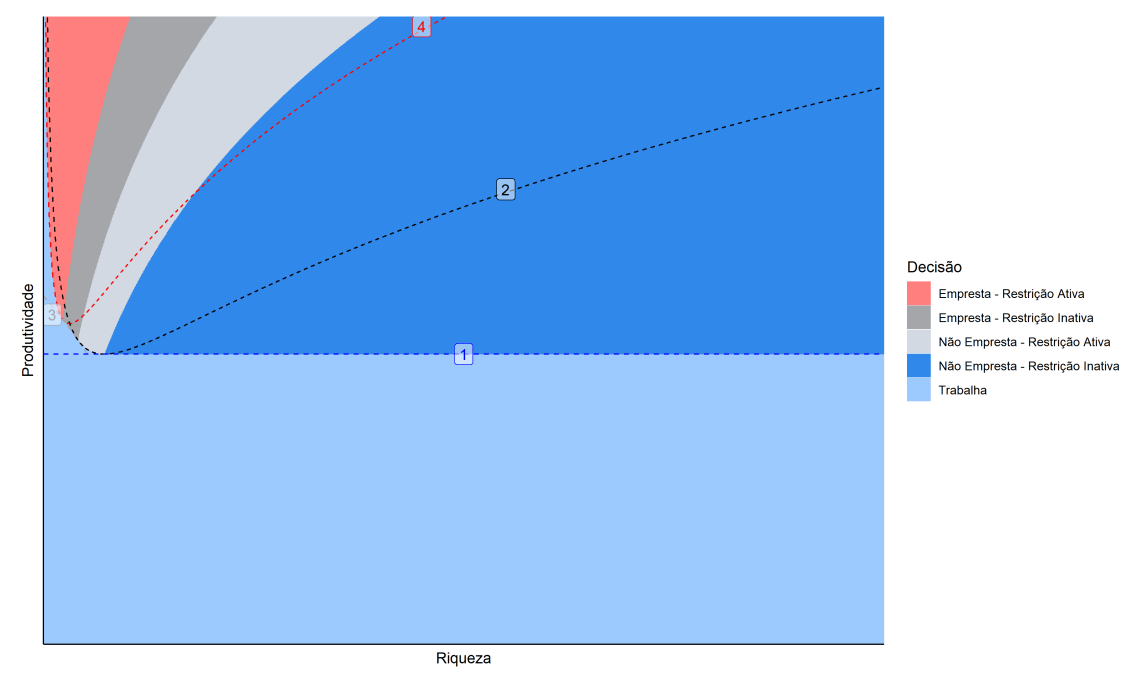

Fonte - Elaboração própria 


\section{APÊNDICE B - Solução do Modelo}

\section{B.1 Problema do Indivíduo}

Inicialmente, iremos abordar o método de solução empregado para o problema do indivíduo, baseado na solução proposta inicialmente em Achdou et al. (2021) e adaptada de modo a contemplar a dimensão extra de heterogeneidade dos indivíduos. Para tanto, tomemos como dados a estratégia conjunta dos bancos, o salário e a taxa de retorno do ativo livre de risco desta economia.

Aplicando o Lema de Itô no processo de difusão associado a $\ln z_{t}$, obtemos que $z_{t}$ também segue um processo de difusão dado por: ${ }^{1}$,

$$
\begin{aligned}
\mathrm{d} z_{t} & =\mu\left(z_{t}\right) \mathrm{d} t+\sigma\left(z_{t}\right) \mathrm{d} W_{t} \\
\mu\left(z_{t}\right) & =\left(-\varphi \ln z_{t}+\frac{\zeta^{2}}{2}\right) z_{t} \\
\sigma\left(z_{t}\right) & =\zeta z_{t}
\end{aligned}
$$

Conforme exposto em Achdou et al. (2021), a solução do problema do indivíduo e a evolução da distribuição conjunta de indivíduos nesta economia são dadas por um par de equações diferenciais acopladas, denominadas de Hamilton-Jacobi-Bellman (HJB) e a Kolmogorov-Forward $(\mathrm{KF})^{2}$. Em estado estacionário, isto é, na situação em que a distribuição conjunta dos tipos de agentes é invariante no tempo, a HJB e a KF são dadas respectivamente por:

$$
\begin{aligned}
& \rho v(a, z, \theta)=\operatorname{máx}_{c}\left\{u(c(a, z, \theta))+\partial_{a} v(a, z, \theta)[y(a, z, \theta)+r a-c(a, z, \theta)]+\partial_{z} v(a, z, \theta) \mu(z)\right. \\
& \left.+\frac{1}{2} \partial_{z z} v(a, z, \theta) \sigma^{2}(z)\right\}
\end{aligned}
$$

$$
0=-\partial_{a}[p(a, z, \theta) g(a, z, \theta)]-\partial_{z}[\mu(z) g(a, z, \theta)]+\frac{1}{2} \partial_{z z}\left[\sigma^{2}(z) g(a, z, \theta)\right]
$$

em que $\mu(z)$ e $\sigma(z)$ são dados na Eq. (B.1), $v(a, z, \theta)$ é a função valor associada ao indivíduo com riqueza, $a$, produtividade, $z$, e posição $\theta, p(a, z, \theta)$ é função que estabelece a decisão de poupança do indivíduo e $g(a, z, \theta)$ é a distribuição conjunta da riqueza, produtividade e posição dos indivíduos. A relação entre a policy function $p(a, z, \theta)$ e a decisão de consumo do indivíduo é dada por $p(a, z, \theta)=y(a, z, \theta)+r a-c(a, z, \theta)$.

\footnotetext{
1 Ver Stokey (2009)

2 Para a derivação da HJB, ver Apêndice A.1
} 
Solucionamos a HJB utilizando uma aproximação via método de diferenças finitas. Para fazer isso, são utilizados grids para representar as variáveis de riqueza, produtividade e posição e assim aproximar a função valor do indivíduo $v(a, z, \theta)$ para cada combinação possível dos pontos destes três grids.

A variável de riqueza será aproximada por um grid de $N_{a}$ pontos equidistantes e a distância entre dois pontos consecutivos é $\Delta a$. O i-ésimo elemento do grid de riqueza será representado por $a_{i}$, com $i=1,2, \ldots, N_{a}$. Aproximaremos a variável $z$ por um grid de $N_{z}$ pontos equidistantes, sendo $\Delta z$ a distância entre dois pontos consecutivos. O j-ésimo elemento do grid de produtividade será representado por $z_{j}$, com $j=1,2, \ldots, N_{z}$. De forma análoga para a variável posição, o grid terá $N_{\theta}$ pontos cuja distância entre dois pontos consecutivos é dada por $\Delta \theta$ e o k-ésimo elemento do grid é representado por $\theta_{k}$, com $k=1,2 \ldots \ldots, N_{\theta}$. Adotaremos as seguintes convenções:

$$
\begin{aligned}
v_{i, j, k} & :=v\left(a_{i}, z_{j}, \theta_{k}\right) \\
c_{i, j, k} & :=c\left(a_{i}, z_{j}, \theta_{k}\right) \\
y_{i, j, k} & :=y\left(a_{i}, z_{j}, \theta_{k}\right) \\
\mu_{j} & :=\mu\left(z_{j}\right) \\
\sigma_{j} & :=\sigma\left(z_{j}\right)
\end{aligned}
$$

Além disso, a n-ésima iteração da função valor e do consumo serão denotadas respectivamente por $v_{i, j, k}^{n}$ e $c_{i, j, k}^{n}$. A partir de um chute inicial $v^{0}$ para a função valor, a aproximação na n-ésima iteração da Eq. (B.2) utilizando a forma semi-implícita ${ }^{3}$ é dada por:

$$
\frac{v_{i, j, k}^{n+1}-v_{i, j, k}^{n}}{\Delta}+\rho v_{i, j, k}^{n+1}=u\left(c_{i, j, k}^{n}\right)+\partial_{a} v_{i, j, k}^{n+1}\left[y_{i, j, k}+r a_{i}-c_{i, j, k}^{n}\right]+\partial_{z} v_{i, j, k}^{n+1} \mu_{j}+\frac{1}{2} \partial_{z z} v_{i, j, k}^{n+1} \sigma_{j}^{2}
$$

em que $c_{i, j, k}^{n}$ é dado pela condição de primeira ordem da Eq. (B.2):

$$
c_{i, j, k}^{n}=\left(u^{\prime}\right)^{-1}\left(\partial_{a} v_{i, j, k}^{n}\right)
$$

O parâmetro $\Delta$ é o tamanho do passo utilizado no processo iterativo. Tipicamente, valores altos para $\Delta$ garantem uma convergência mais rápida. A escolha da forma semi-implícita baseia-se na elevada rapidez e estabilidade do processo de convergência,

3 Semi-implícita pois o consumo do indivíduo ainda é calculado a partir da iteração $n$, e não $n+1$, da função valor. Uma versão implícita poderia ser utilizada, mas não teríamos uma solução analítica para $v^{n+1}$ em função da iteração atual da função valor $v^{n}$. Recorreríamos a algum método numérico para determinar $v^{n+1}$ neste caso. 
independente do tamanho de $\Delta$, conforme mostrado em Candler (2001). Os diferenciais da Eq. (B.4) serão aproximados usando o método de diferenças finitas combinado com "Upwind Scheme". Neste esquema, utiliza-se ora a diferença forward, quando o drift da variável de estado for positivo, ora a diferença backward, quando o drift da variável de estado for negativo. O drift da variável de estado no caso da riqueza é dado por: $y_{i, j, k}+r a_{i}-c_{i, j, k}^{n}$. No caso da produtividade é dado por: $\mu_{j}$. As diferenças forward e backward para o diferencial da função valor em relação a riqueza são dadas respectivamente por:

$$
\begin{aligned}
\partial_{a, F} v_{i, j, k} & =\frac{v_{i+1, j, k}-v_{i, j, k}}{\Delta a} \\
\partial_{a, B} v_{i, j, k} & =\frac{v_{i, j, k}-v_{i-1, j, k}}{\Delta a}
\end{aligned}
$$

Analogamente para o diferencial da função valor em relação ao z, com exceção da derivada de segunda ordem que será aproximada utilizando a diferença central:

$$
\begin{aligned}
\partial_{z, F} v_{i, j, k} & =\frac{v_{i, j+1, k}-v_{i, j, k}}{\Delta z} \\
\partial_{z, B} v_{i, j, k} & =\frac{v_{i, j, k}-v_{i, j-1, k}}{\Delta z} \\
\partial_{z z} v_{i, j, k} & =\frac{v_{i, j+1, k}-2 v_{i, j, k}+v_{i, j-1, k}}{\Delta z}
\end{aligned}
$$

Com base na Eq. (B.6), definimos o consumo obtido via diferença forward, $c_{i, j, k, F}$, e via diferença backward, $c_{i, j, k, B}$, e as respectivas poupanças forward, $s_{i, j, k, F}$, e backward, $s_{i, j, k, B}$, por:

$$
\begin{aligned}
c_{i, j, k, F}^{n} & =\left(u^{\prime}\right)^{-1}\left(\partial_{a, F} v_{i, j, k}^{n}\right) \\
c_{i, j, k, B}^{n} & =\left(u^{\prime}\right)^{-1}\left(\partial_{a, B} v_{i, j, k}^{n}\right) \\
s_{i, j, k, F}^{n} & =y_{i, j, k}+r a_{i}-c_{i, j, k, F}^{n} \\
s_{i, j, k, B}^{n} & =y_{i, j, k}+r a_{i}-c_{i, j, k, B}^{n}
\end{aligned}
$$

Dado a concavidade da função valor, teremos $\partial_{a, F} v_{i, j, k}<\partial_{a, B} v_{i, j, k}$, donde $s_{i, j, k, F}^{n}<$ $s_{i, j, k, B}^{n}$. Logo, não ocorrerá simultaneamente $s_{i, j, k, F}>0$ e $s_{i, j, k, B}<0$. Portanto há três casos a serem considerados para o cálculo de consumo e poupança utilizando o "Upwind Scheme": $s_{i, j, k, F}>0$ ou $s_{i, j, k, B}<0$ ou $s_{i, j, k, F} \leq 0 \leq s_{i, j, k, B}$. Nos dois primeiros casos a escolha é trivial, no último caso, definimos a poupança como sendo nula. Portanto: 


$$
\begin{gathered}
s_{i, j, k}^{n}= \begin{cases}s_{i, j, k, F}^{n} & \text { se } s_{i, j, k, F}>0 \\
s_{i, j, k, B}^{n} & \text { se } s_{i, j, k, B}<0 \\
0 & \text { se } s_{i, j, k, F} \leq 0 \leq s_{i, j, k, B}\end{cases} \\
c_{i, j, k}^{n}= \begin{cases}c_{i, j, k, F}^{n} & \text { se } s_{i, j, k, F}>0 \\
c_{i, j, k, B}^{n} & \text { se } s_{i, j, k, B}<0 \\
y_{i, j, k}+r a_{i} & \text { se } s_{i, j, k, F} \leq 0 \leq s_{i, j, k, B}\end{cases}
\end{gathered}
$$

Substituindo as Eqs. (B.6) a (B.9) na Eq. (B.4), temos:

$$
\begin{gathered}
\frac{v_{i, j, k}^{n+1}-v_{i, j, k}^{n}}{\Delta}+\rho v_{i, j, k}^{n+1}=u\left(c_{i, j, k}^{n}\right)+\frac{v_{i+1, j, k}^{n+1}-v_{i, j, k}^{n+1}}{\Delta a}\left(s_{i, j, k, F}^{n}\right)^{+}+\frac{v_{i, j, k}^{n+1}-v_{i-1, j, k}^{n+1}}{\Delta a}\left(s_{i, j, k, B}^{n}\right)^{-} \\
+\frac{v_{i, j+1, k}^{n+1}-v_{i, j, k}^{n+1}}{\Delta z} \mu_{j}^{+}+\frac{v_{i, j, k}^{n+1}-v_{i, j-1, k}^{n+1}}{\Delta z} \mu_{j}^{-}+\frac{\sigma_{j}^{2}}{2} \frac{v_{i, j+1, k}^{n+1}-2 v_{i, j, k}^{n+1}+v_{i, j-1, k}^{n+1}}{(\Delta z)^{2}} \quad \text { (B.10) }
\end{gathered}
$$

Rearranjando a expressão acima e agrupando os termos com índices iguais, temos:

$$
\begin{array}{r}
\frac{v_{i, j, k}^{n+1}-v_{i, j, k}^{n}}{\Delta}+\rho v_{i, j, k}^{n+1}=u\left(c_{i, j, k}^{n}\right)+v_{i-1, j, k}^{n+1} x_{i, j, k}+v_{i, j . k}^{n+1}\left(\Omega_{i, j, k}+\xi_{j}\right)+v_{i+1, j, k}^{n+1} \Phi_{i, j, k} \\
+v_{i, j-1, k}^{n+1} \Gamma_{j}+v_{i, j+1, k}^{n+1} \varphi_{j}
\end{array}
$$

em que os elementos $x_{i, j, k}, \Omega_{i, j, k}, \Phi_{i, j, k}, \Gamma_{j}, \xi_{j}, \varphi_{j}$ são dados por:

$$
\begin{aligned}
x_{i, j, k} & =-\frac{\left(s_{i, j, k, B}^{n}\right)^{-}}{\Delta a} \\
\Omega_{i, j, k} & =-\frac{\left(s_{i, j, k, F}^{n}\right)^{+}}{\Delta a}+\frac{\left(s_{i, j, k, B}^{n}\right)^{-}}{\Delta a} \\
\Phi_{i, j, k} & =\frac{\left(s_{i, j, k, F}^{n}\right)^{+}}{\Delta a} \\
\Gamma_{j} & =-\frac{\mu_{j}^{-}}{\Delta z}+\frac{\sigma_{j}^{2}}{2(\Delta z)^{2}} \\
\xi_{j} & =\frac{\mu_{j}^{-}}{\Delta z}-\frac{\mu_{j}^{+}}{\Delta z}-\frac{\sigma_{j}^{2}}{(\Delta z)^{2}} \\
\varphi_{j} & =\frac{\mu_{j}^{+}}{\Delta z}+\frac{\sigma_{j}^{2}}{2(\Delta z)^{2}}
\end{aligned}
$$

Nas extremidades do grid de riqueza, temos, para todo $j$ e $k, x_{1, j, k}=\Phi_{N_{a}, j, k}=0$ de modo que $v_{0, j, k}$ e $v_{N_{a}+1, j, k}$ não são utilizados ${ }^{4}$.

4 De fato, se $x_{1, j, k} \neq 0$, teríamos $\left(s_{1, j, k, B}^{n}\right)^{-}<0$, e o indivíduo reduziria sua riqueza, atingindo um nível de riqueza inferior ao menor elemento do grid. Raciocínio análogo se aplica a $\Phi_{N_{a}, j, k} \neq 0$. 
Assumimos que o processo de difusão é refletido nos limites inferior e superior do grid de produtividade ${ }^{5}$. Com essa hipótese, pode ser mostrado que $\partial_{z} v\left(a, z_{1}, \theta\right)=$ $\partial_{z} v\left(a, z_{N_{z}}, \theta\right)=0{ }^{6}$. Temos, portanto, $v_{i, 0, k}=v_{i, 1, k}$ e $v_{i, N_{z}+1, k}=v_{i, N_{z}, k}$. Assim, na extremidade inferior do grid de produtividade, a Eq. (B.11) se torna:

$\frac{v_{i, 1, k}^{n+1}-v_{i, 1, k}^{n}}{\Delta}+\rho v_{i, 1}^{n+1}=u\left(c_{i, 1, k}^{n}\right)+v_{i-1,1, k}^{n+1} x_{i, 1, k}+v_{i, 1, k}^{n+1}\left(\Omega_{i, 1, k}+\xi_{1}+\Gamma_{1}\right)+v_{i+1,1, k}^{n+1} \Phi_{i, 1, k}+v_{i, 2, k}^{n+1} \varphi_{1}$

e na extremidade superior do grid de produtividade, a Eq. (B.11) se torna:

$$
\begin{aligned}
\frac{v_{i, N_{z}, k}^{n+1}-v_{i, N_{z}, k}^{n}}{\Delta}+\rho v_{i, N_{z}, k}^{n+1}=u\left(c_{i, N_{z}, k}^{n}\right)+v_{i-1, N_{z}, k}^{n+1} x_{i, N_{z}, k} & +v_{i, N_{z}, k}^{n+1}\left(\Omega_{i, N_{z}, k}+\xi_{N_{z}}+\varphi_{N_{z}}\right) \\
& +v_{i+1, N_{z}, k}^{n+1} \Phi_{i, N_{z}, k}+v_{i, N_{z}-1, k}^{n+1} \Gamma_{N_{z}}
\end{aligned}
$$

Fixado um elemento do grid de posição $\theta_{k}$, a Eq. (B.11) se torna um sistema linear de $N_{a} \cdot N_{z}$ equações, podendo ser expresso na forma matricial por:

$$
\overrightarrow{\boldsymbol{v}}_{k}^{n+1}=\left[\left(\frac{1}{\Delta}+\rho\right) \mathbf{I}-\mathbf{A}_{k}^{n}\right]^{-1}\left[\overrightarrow{\boldsymbol{u}}_{k}^{n}+\frac{1}{\Delta} \overrightarrow{\boldsymbol{v}}_{k}^{n}\right]
$$

em que $\overrightarrow{\boldsymbol{v}}_{k}^{n}$ e $\overrightarrow{\boldsymbol{u}}_{k}^{n}$ são vetores de tamanho $N_{a} \cdot N_{z}$ com entradas dadas respectivamente por:

$$
\begin{aligned}
\overrightarrow{\boldsymbol{v}}_{k}^{n} & =\left(v_{1,1, k}^{n}, \ldots, v_{N_{a}, 1, k}^{n}, v_{1,2, k}^{n}, \ldots, v_{N_{a}, 2, k}^{n}, \ldots, v_{N_{a}, N_{z}, k}^{n}\right) \\
\overrightarrow{\boldsymbol{u}}_{k}^{n} & =\left(u_{1,1, k}^{n}, \ldots, u_{N_{a}, 1, k}^{n}, u_{1,2, k}^{n}, \ldots, u_{N_{a}, 2, k}^{n}, \ldots, u_{N_{a}, N_{z}, k}^{n}\right)
\end{aligned}
$$

e $\mathbf{A}_{k}^{n}$ é uma matriz quadrada $\left(N_{a} \cdot N_{z}\right) \times\left(N_{a} \cdot N_{z}\right)$ definida como:

$$
\mathbf{A}_{k}^{n}=\tilde{\mathbf{A}}_{k}^{n}+\mathbf{C}
$$

sendo $\tilde{\mathbf{A}}_{k}^{n}$ e C dadas pelas Eqs. (B.18) e (B.19).

A partir de um chute inicial $\overrightarrow{\boldsymbol{v}}_{k}^{0}$, procede-se de forma iterativa aplicando a Eq. (B.13) até que a distância entre duas iterações sucessivas seja suficientemente próxima a zero.

Para determinar a distribuição estacionária de indivíduos do modelo, utilizamos o fato de que o operador diferencial que surge na Kolmogorov-Forward, dada na Eq. (B.3), é o operador adjunto da equação Hamilton-Jacobi-Bellman, conforme Achdou et al. (2021). Desta forma, após a convergência do processo iterativo, digamos na iteração $\bar{n}$, a distribuição condicional de indivíduos dado que a posição é $\theta=\theta_{k}, g\left(a, z \mid \theta=\theta_{k}\right)$, é dada por:

$$
\left(\mathbf{A}_{k}^{\bar{n}}\right)^{\mathrm{T}} \mathbf{g}\left(a, z \mid \theta=\theta_{k}\right)=\mathbf{0}
$$

\footnotetext{
5 Um processo $x_{t}$ é dito refletido em um limite superior $b$ se ele pode se movimentar livremente enquanto $x_{t} \leq b$ mas, se $x_{t}=b$ e o próximo incremento $\mathrm{d} x$ for positivo, então o sinal desse incremento é trocado, como se o limite superior atuasse como um espelho. Analogamente para o limite inferior.

6 Ver Dixit (1993, p. 26)
} 
em que $\left(\mathbf{A}_{k}^{\bar{n}}\right)^{\mathrm{T}}$ é a transposta da matriz $\mathbf{A}_{k}^{\bar{n}}$.

Repetindo o procedimento acima para todos os pontos do grid de posição, isto é, solucionando a Eq. (B.13) iterativamente e obtendo $g\left(a, z \mid \theta=\theta_{k}\right)$ via Eq. (B.16), obtemos a solução do problema do indivíduo para todos as combinações possíveis dos três grids. Como os indivíduos estão distribuídos de forma uniforme ao longo da circunferência, a distribuição de tipos de indivíduos nessa economia será dada por:

$$
\mathbf{g}\left(a, z, \theta_{k}\right)=\frac{1}{2 \pi} \mathbf{g}\left(a, z \mid \theta=\theta_{k}\right)
$$




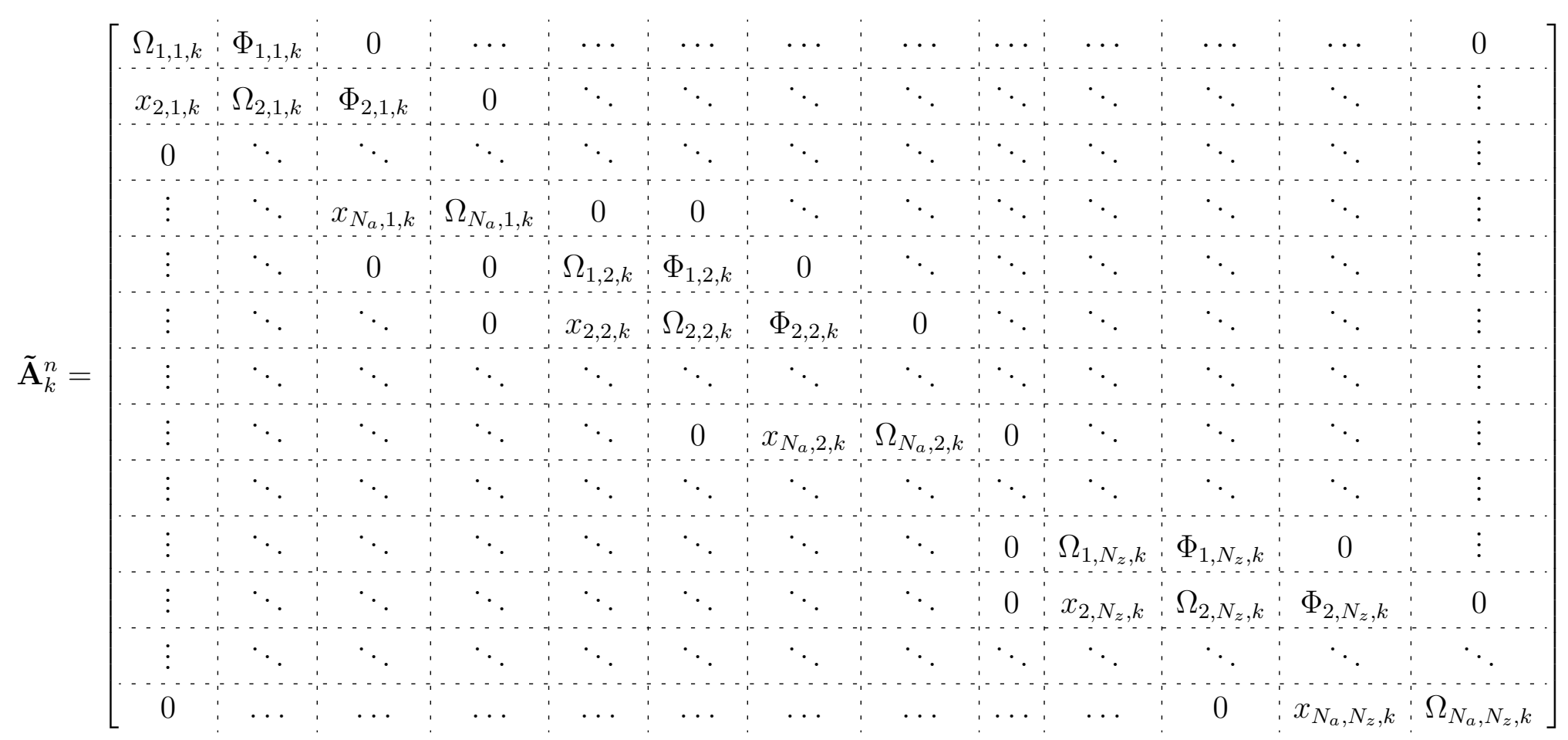

(B.18) 


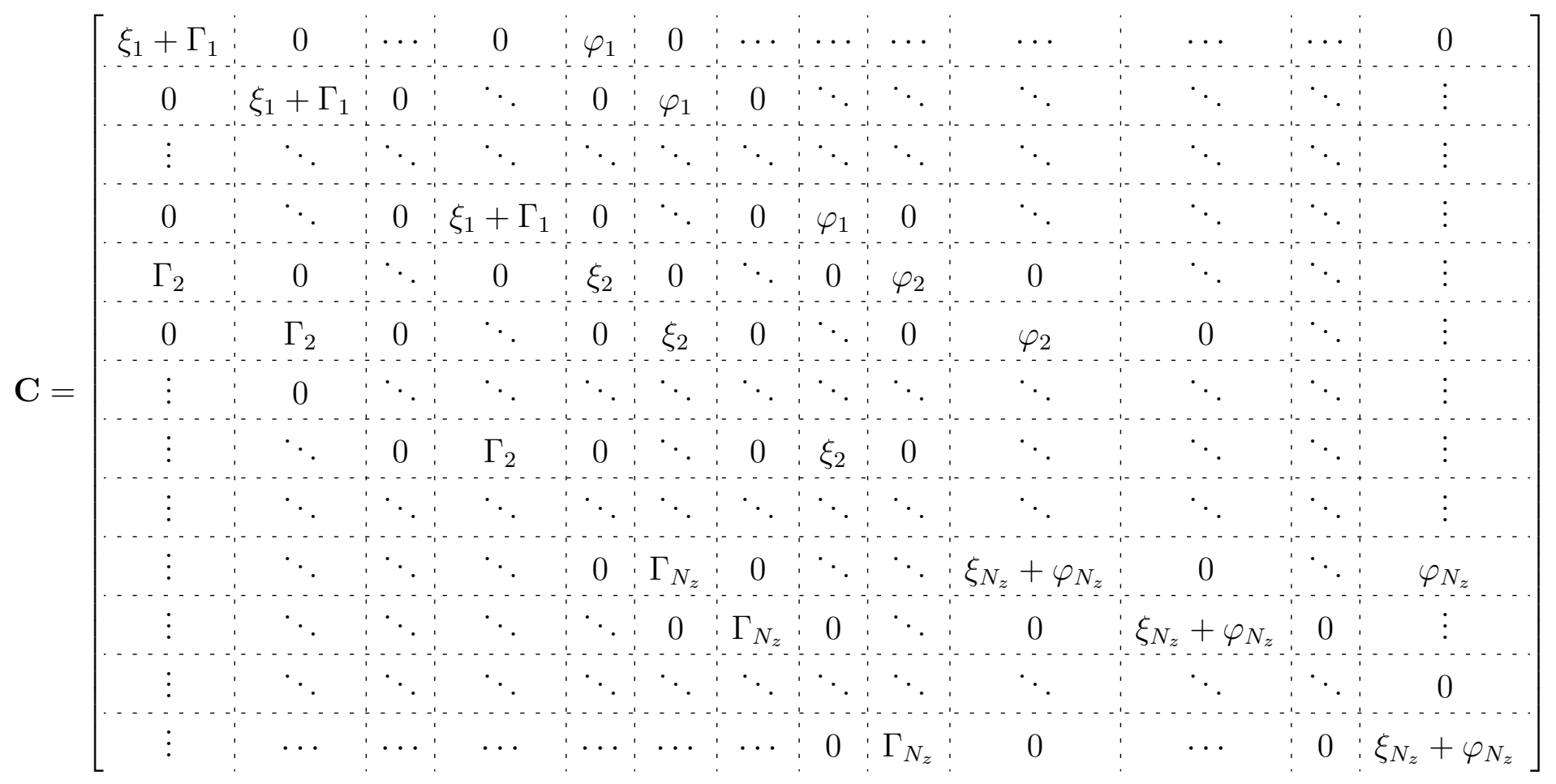




\section{B.2 Market clearing}

Tomando como dado a estratégia conjunta dos bancos, para um $w$ e $r$ qualquer, podemos definir uma função de excesso de demanda agregada, $\mathbf{E}: \mathbb{R}_{++}^{2} \rightarrow \mathbb{R}^{2}$, que nos fornece o excesso de demanda nos mercados de trabalho, $E_{\ell}(r, w)$, e de crédito, $E_{c}(r, w)$, de forma que a função $\mathbf{E}$ é dada por $\mathbf{E}(r, w):=\left(E_{\ell}(r, w), E_{c}(r, w)\right)$. Rearranjando a Eq. (3.11), temos:

$$
E_{\ell}(r, w)=\int_{0}^{2 \pi} \int_{\underline{z}}^{\bar{z}} \int_{\underline{a}}^{\bar{a}} \ell(\cdot) g(a, z, \theta) \mathbb{1}_{\left\{\pi^{i}>w\right\}} \mathrm{d} a \mathrm{~d} z \mathrm{~d} \theta-\int_{0}^{2 \pi} \int_{\underline{z}}^{\bar{z}} \int_{\underline{a}}^{\bar{a}} g(a, z, \theta) \mathbb{1}_{\left\{\pi^{i} \leq w\right\}} \mathrm{d} a \mathrm{~d} z \mathrm{~d} \theta
$$

rearranjando Eq. (3.12), temos:

$$
\begin{aligned}
E_{c}(r, w)=\int_{0}^{2 \pi} \int_{\underline{z}}^{\bar{z}} \int_{\underline{a}}^{\bar{a}}(k(\cdot)-a) g(a, z, \theta) \mathbb{1}_{\left\{\pi^{i}>w\right\}} \mathbb{1}_{\left\{\pi_{e, j_{i}^{\prime}}>\pi_{a}^{i}\right\}} \mathrm{d} a \mathrm{~d} z \mathrm{~d} \theta \\
-(1-\chi)\left[\int_{0}^{2 \pi} \int_{\underline{z}}^{\bar{z}} \int_{\underline{a}}^{\bar{a}} a g(a, z, \theta) \mathbb{1}_{\left\{\pi^{i} \leq w\right\}} \mathrm{d} a \mathrm{~d} z \mathrm{~d} \theta+\right. \\
\\
\left.\int_{0}^{2 \pi} \int_{\underline{z}}^{\bar{z}} \int_{\underline{a}}^{\bar{a}}(a-k(\cdot)) g(a, z, \theta) \mathbb{1}_{\left\{\pi^{i}>w\right\}} \mathbb{1}_{\left\{\pi_{e, j_{i}^{\prime}}^{i} \leq \pi_{a}^{i}\right\}} \mathrm{d} a \mathrm{~d} z \mathrm{~d} \theta\right]
\end{aligned}
$$

Buscamos $r$ e $w$ tais que $\mathbf{E}(r, w)=\mathbf{0}$. Para tanto, utilizamos os grids definidos na seção anterior e aproximamos as integrais acima utilizando o método dos trapézios ${ }^{7}$. Com base nessas aproximações, empregamos o método "Trust Region" para determinar a solução numérica para este sistema de equações não lineares ${ }^{8}$.

\section{B.3 Problema dos Bancos}

\section{B.3.1 Caso simétrico}

Consideraremos primeiro o caso em que há um único custo por unidade de deslocamento no modelo e a disposição dos bancos é tal que a distância entre dois bancos adjacentes é a mesma. Desta forma, dada a simetria do modelo, procuramos um equilíbrio de Nash simétrico em que todos os bancos escolhem a mesma estratégia.

Construímos um grid de estratégias com $N_{s}$ pontos, $\left(s^{1}, s^{2} \ldots s^{N_{s}}\right)$ e, dada a simetria do problema, calculamos o lucro de um dos bancos, digamos o banco $j=1$, em

7 Para mais detalhes sobre método dos trapézios, ver Judd (1998, p. 253)

8 Tipicamente, as linguagens de programação atuais contém um pacote de otimização que implementa esse algoritmo, como a função "fsolve" no Matlab ou "NLsolve" no Julia. Para mais detalhes sobre o método "Trust Region", ver Coleman e Li (1996). 
equilíbrio, para cada combinação possível em que o banco 1 escolhe um dos elementos do grid e os demais bancos escolhem outro elemento do grid. Definindo o vetor de estratégias $\mathbf{s}^{a, b}$ como:

$$
\mathbf{s}^{a, b}=(s^{a}, \underbrace{s^{b}, s^{b}, \ldots, s^{b}}_{N_{\text {bancos }}-1}), \quad a, b \in\left[1,2,3, \ldots, N_{s}\right]
$$

isto é, o vetor em que o banco 1 escolhe o a-ésimo elemento do grid e todos os demais bancos escolhem o b-ésimo elemento, construímos uma matriz de payoffs $\mathbf{P}, N_{s} \times N_{s}$, em que o elemento da linha $a$ e coluna $b, p_{a, b}$, dessa matriz é dado por:

$$
p_{a, b}=\pi_{1}^{\text {banco }}\left(s^{a}, \mathbf{s}_{-1}^{a, b}\right), \quad a, b \in\left[1,2,3, \ldots, N_{s}\right]
$$

ou seja, $p_{a, b}$ é o lucro do banco 1 quando este escolhe o a-ésimo elemento do grid, $s^{a}$, e os demais bancos escolhem o b-ésimo elemento do grid, $s^{b}$. O equilíbrio de Nash será o elemento $\bar{a}$ do grid de estratégias que satisfaz:

$$
p_{\bar{a}, \bar{a}} \geq p_{b, \bar{a}}, \forall b \in\left[1,2, \ldots, N_{s}\right]
$$

Para calcular a Eq. (B.21), aproximamos a Eq. (3.9) utilizando os grids definidos no Apêndice B.1 e o método dos trapézios no cálculo das integrais.

\section{B.3.2 Caso não simétrico}

Para o caso não simétrico, utilizamos o método Distance to Nash, semelhante à encontrada em Townsend e Zhorin (2015). Denotaremos por $S_{\text {grid }}$ o conjunto formado por todos os elementos do grid de de estratégias e por $\mathbf{S}=S_{\text {grid }}^{N_{\text {bancos }}}$ o conjunto de estratégias conjuntas dos bancos. Para cada estratégia conjunta $\mathbf{S}=\left(s_{1}, s_{2}, \ldots, s_{N_{\text {bancos }}}\right) \in \mathbf{S}$ e para cada banco $j \in \mathcal{J}$, calculamos

$$
\pi_{j}^{\text {banco }}\left(s_{j}^{*}, \mathbf{s}_{-j}\right)=\operatorname{máx}_{s_{j}^{\prime} \in S_{\text {grid }}}\left\{\pi_{j}^{\text {banco }}\left(s_{j}^{\prime}, \mathbf{s}_{-j}\right)\right\}-\pi_{j}^{\text {banco }}\left(s_{j}, \mathbf{s}_{-j}\right)
$$

isto é, para uma dada estratégia conjunta $\mathbf{s}, s_{j}^{*}$ é a estratégia do banco $j$ que proporciona a ele o maior ganho ao desviar da estratégia conjunta s. A seguir, calculamos a Distance to Nash como:

$$
\operatorname{dist}(\mathbf{s})=\sum_{j \in \mathcal{J}} \pi_{j}^{\text {banco }}\left(s_{j}^{*}, \mathbf{s}_{-j}\right)
$$

por fim, minimizamos a expressão acima com relação a s:

$$
\hat{\mathbf{s}}=\underset{\mathbf{s} \in \mathbf{S}}{\operatorname{argmin}}\{\operatorname{dist}(\mathbf{s})\}
$$

Em um equilíbrio de Nash, temos dist $(\hat{\mathbf{s}})=0$. Utilizamos esta métrica para criar um ranking de candidatos ao Equilíbrio de Nash mesmo no caso em que não há ou não conseguimos achar uma estratégia conjunta que seja Equilíbrio de Nash. 


\section{APÊNDICE C - Algoritmos}

\section{C.1 Problema do Indivíduo}

Dados os grids de riqueza, produtividade, e posição, um critério de parada, os preços e uma estratégia conjunta dos bancos, procedemos da seguinte forma:

1. Escolhemos um elemento do grid de posição $\theta_{k}$

2. Resolve-se o problema da firma e de escolha ocupacional do indivíduo, obtendo a renda $y\left(a_{i}, z_{j}, \theta_{k}\right)$

3. Para o chute inicial da função valor, assumimos que a decisão de poupança é nula. Portanto:

$$
v_{i, j, k}^{0}=\frac{u\left(y\left(a_{i}, z_{j}, \theta_{k}\right)+r a_{i}\right)}{\rho}
$$

4. Obtermos o vetor $\overrightarrow{\boldsymbol{v}}_{k}^{0}$ utilizando a Eq. (B.14)

5. Resolvemos de forma iterativa a Eq. (B.13) até que a distância entre duas iterações sucessivas, dada por $\left\|\overrightarrow{\boldsymbol{v}}_{k}^{n+1}-\overrightarrow{\boldsymbol{v}}_{k}^{n}\right\|_{\infty}$, seja menor que o critério de parada.

6. Obtemos a distribuição estacionária de indivíduos resolvendo o sistema linear dado pela Eq. (B.16). Tal sistema linear é indeterminado, admitindo infinitas soluções. Para determinar a solução, impomos também a condição:

$$
\int_{\underline{z}}^{\bar{z}} \int_{\underline{a}}^{\bar{a}} g\left(a, z \mid \theta=\theta_{k}\right) \mathrm{d} a \mathrm{~d} z=1
$$

em que a integral acima é aproximada utilizando método dos trapézios.

7. Repetimos os itens 1 a 6 para todos os elementos do grid de posição.

\section{C.2 Equilíbrio de Estado Estacionário}

Definido um grid de estratégias $\left(s^{1}, s^{2}, \ldots, s^{N_{s}}\right)$, procederemos da seguinte forma:

\section{Caso simétrico:}

1. Para um par $(a, b)$, com $a, b \in\left[1,2, \ldots, N_{S}\right]$, forme a seguinte estratégia conjunta dos bancos: $\mathbf{s}^{a, b}=\left(s^{a}, s^{b}, s^{b}, \ldots, s^{b}\right)$.

2. Determine $r$ e $w$ que equilibram os mercados de crédito e trabalho, conforme descrito na Apêndice B.1 
3. Para $r$ e $w$ encontrados, calcule o lucro do banco $j=1, p_{a, b}$, conforme Eq. (B.21).

4. Repita os itens 1 a 3 para cada uma das $N_{s}^{2}$ combinações possíveis de estratégias conjuntas da forma $\mathbf{s}^{a, b}$, com $a, b \in\left[1,2, \ldots, N_{s}\right]$, obtendo assim a matriz de payoffs $\mathbf{P}$.

5. Determine a estratégia $s^{\bar{a}}$ conforme Eq. (B.22).

\section{Caso não simétrico:}

1. Para cada estratégia conjunta $\mathbf{s} \in \mathbf{S}$. Determine $r$ e $w$ que equilibram os mercados de crédito e trabalho, conforme descrito na Apêndice B.1

2. Para $r$ e $w$ encontrados, calcule o lucro de cada um dos bancos.

3. Repita os itens 1 a 2 para cada uma das $N_{s}^{N_{\text {bancos }}}$ possíveis estratégias conjuntas dos bancos.

4. Para cada estratégia conjunta $\mathbf{s} \in \mathbf{S}$, determine dist(s) conforme Eq. (B.24).

5. Determine $\hat{s}$ conforme Eq. (B.25). 